San Jose State University

SJSU ScholarWorks

Master's Theses

Master's Theses and Graduate Research

Spring 2017

\title{
The Impact of a Changing Climate on the Frequency of Sudden Stratospheric Warming Events
}

Ashley Fortin

San Jose State University

Follow this and additional works at: https://scholarworks.sjsu.edu/etd_theses

\section{Recommended Citation}

Fortin, Ashley, "The Impact of a Changing Climate on the Frequency of Sudden Stratospheric Warming Events" (2017). Master's Theses. 4797. DOI: https://doi.org/10.31979/etd.2ej3-4tzw

https://scholarworks.sjsu.edu/etd_theses/4797

This Thesis is brought to you for free and open access by the Master's Theses and Graduate Research at SJSU ScholarWorks. It has been accepted for inclusion in Master's Theses by an authorized administrator of SJSU ScholarWorks. For more information, please contact scholarworks@sjsu.edu. 


\title{
THE IMPACT OF A CHANGING CLIMATE ON THE FREQUENCY OF SUDDEN STRATOSPHERIC WARMING EVENTS
}

\author{
A Thesis \\ Presented to \\ The Faculty of the Department of Meteorology and Climate Science \\ San José State University \\ In Partial Fulfillment \\ of the Requirements for the Degree \\ Master of Science \\ by \\ Ashley Fortin
}

May 2017 
(C)2017

Ashley Fortin

ALL RIGHTS RESERVED 
The Designated Thesis Committee Approves the Thesis Titled

\section{THE IMPACT OF A CHANGING CLIMATE ON THE FREQUENCY OF SUDDEN STRATOSPHERIC WARMING EVENTS}

by

Ashley Fortin

\section{APPROVED FOR THE DEPARTMENT OF METEOROLOGY AND CLIMATE SCIENCE}

\section{SAN JOSE STATÉ UNIVERSITY}

May 2017

Eugene Cordero, Ph.D.

Minghui Diao, Ph.D.

Martin Leach, Ph.D.
Department of Meteorology and Climate Science

Department of Meteorology and Climate Science

Department of Meteorology and Climate Science 


\title{
ABSTRACT \\ THE IMPACT OF A CHANGING CLIMATE ON THE FREQUENCY OF SUDDEN STRATOSPHERIC WARMING EVENTS
}

\author{
By Ashley Fortin
}

A sudden stratospheric warming (SSW) event is a rapid breakdown of the polar vortex during the winter months. Driven primarily by anomalous planetary-scale Rossby waves propagating upward from the troposphere, SSW events are able to influence tropospheric weather through stratospheric-tropospheric coupling. As a result of increased greenhouse gas emissions, temperatures are changing across the troposphere and may influence how the stratosphere and troposphere interact. It is unclear how the stratospheric circulation will respond to these changes and how the frequency of SSW events may be affected. This study uses National Center for Environmental Prediction and National Center for Atmospheric Research reanalysis data and four phase 5 Coupled Model Intercomparison Project (CMIP5) models to examine the frequency of SSW events in historical datasets from 1950-2005. Representative Concentration Pathways 4.5 and 8.5 are used to analyze how the frequency of SSW events from 2006-2100 differ from historical CMIP5 results. This study found there is a statistically significant increase in SSW events in the future. Mechanisms that influence the changes in SSW event frequency are discussed. 


\section{ACKNOWLEDGMENTS}

This paper would not be in complete form if it were not for the tireless and relentless efforts of Dr. Cordero's advising, encouragement, and support during the past three years. If it were not for my friends and fellow students at San José State University, I may have thrown in the towel a long time ago. The hours you spent by my side, helping me crack the code and encouraging me to keep working hard gave me the motivation needed to continue pursuing this research project. To all of you, I extend an extra special thank you. I would like to thank my parents and family for listening to me during all of our late phone conversations and telling me "if anyone can do this, you can", I would not be the person I am today without your guidance. I would also like to acknowledge Andrew J. Charlton for taking the time to discuss his methodology in detail with me. It truly was the turning point in this research. Lastly, I would like to acknowledge the World Climate Research Programme's Working Group on Coupled Modelling, which is responsible for CMIP, and I thank the climate modeling groups (listed in Table 1 of this paper) for producing and making available their model output. For CMIP the U.S Department of Energy’s Program for Climate Model Diagnosis and Intercomparison provides coordinating support and led development of software infrastructure in partnership with the Global Organization for Earth System Science Portals. 


\section{TABLE OF CONTENTS}

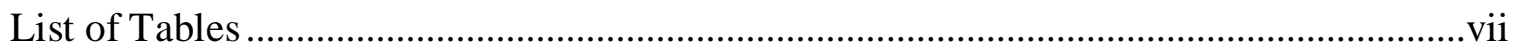

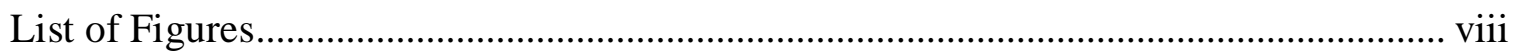

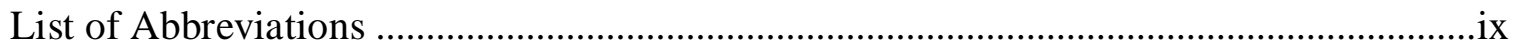

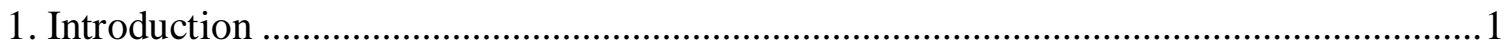

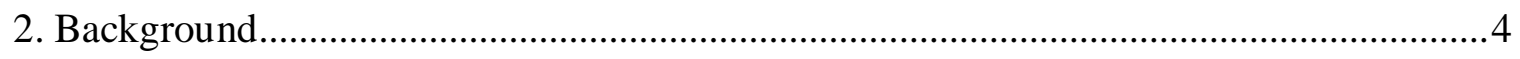

a. Defining sudden stratospheric warming events ...................................................... 4

b. Stratospheric-tropospheric coupling .................................................................... 8

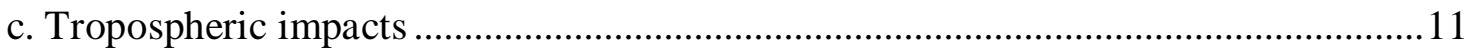

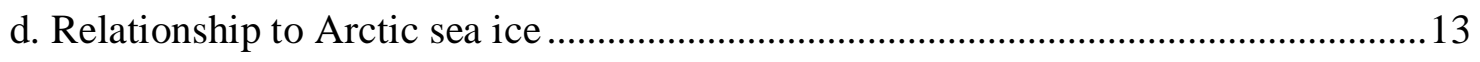

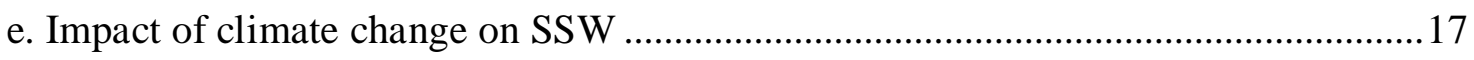

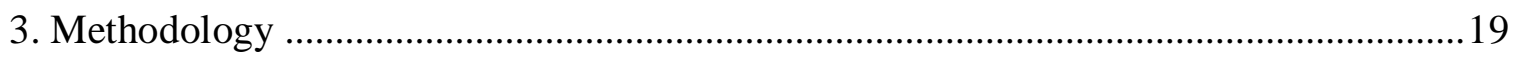

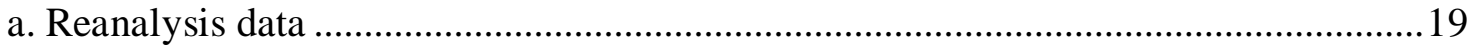

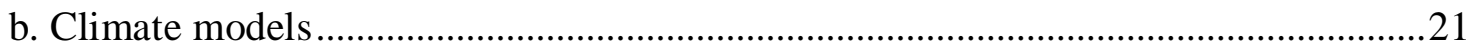

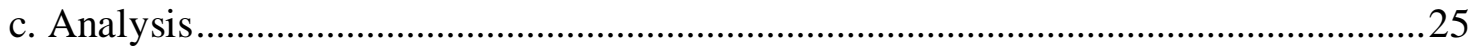

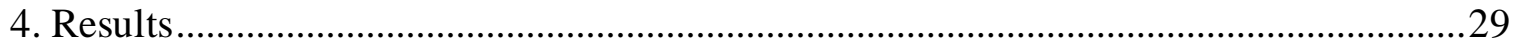

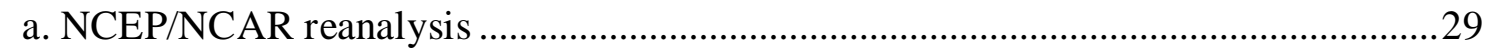

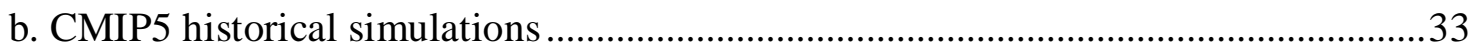

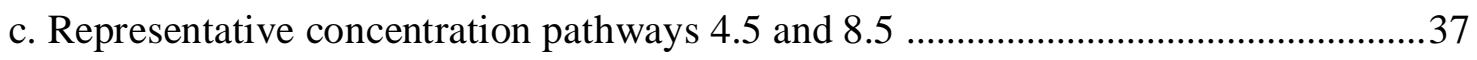

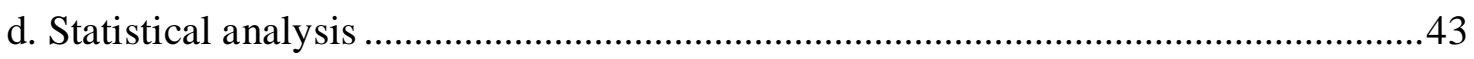

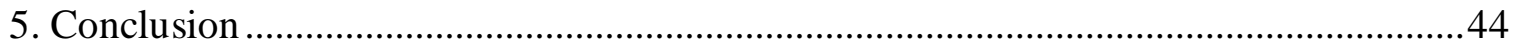

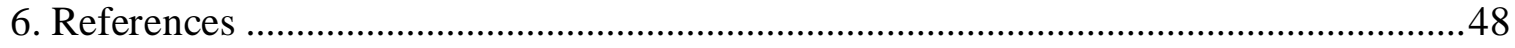

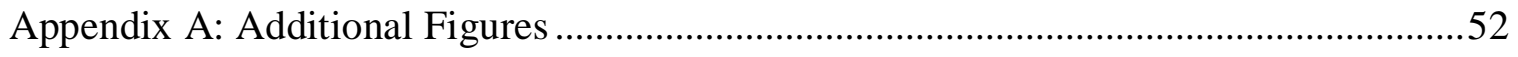




\section{LIST OF TABLES}

Table 1. List of all CMIP5 models used in this study

Table 2. Summary of historical SSW events from 1950-2005.

Table 3. Summary of RCP 4.5 and 8.5 SSW events from 2006-2100. .39

Table 4. Summary of RCP 4.5 and 8.5 SSW events from 2006-2050

Table 5. Summary of RCP 4.5 and 8.5 SSW events from 2050-2100

Table 6. Change in SSW event frequency for RCP 4.5 and 8.5 between 2006-2050 and 2050-2100.

Table 7. Two-tailed paired t-test results using historical ensemble averages from 1955-2005 and RCP 4.5 and 8.5 ensemble averages from 2050-2100. 


\section{LIST OF FIGURES}

Fig. 1. Conceptual model of a north polar stereographic projection showing a vortex displacement event and a vortex split event at $10 \mathrm{hPa}$

Fig. 2. Daily zonally averaged zonal winds at $60^{\circ} \mathrm{N}$ and $10 \mathrm{hPa}$ in NCEP/NCAR reanalysis data from 1 June 1995 to 1 June 1996.

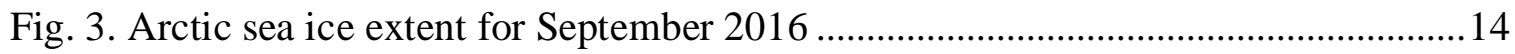

Fig. 4. Schematic model of the process used to identify a SSW event .............................27

Fig. 5. Daily zonally averaged zonal winds at $60^{\circ} \mathrm{N}$ and $10 \mathrm{hPa}$ from $1950-2005$ using NCEP/NCAR Reanalysis data.

Fig. 6. Daily zonally averaged zonal winds at $60^{\circ} \mathrm{N}$ and $10 \mathrm{hPa}$ from $1995-2005$ using NCEP/NCAR Reanalysis data

Fig. 7. Daily zonally averaged zonal winds at $60^{\circ} \mathrm{N}$ and $10 \mathrm{hPa}$ from June 2000 to June 2001

Fig. 8. Daily zonally averaged zonal winds at $60^{\circ} \mathrm{N}$ and $10 \mathrm{hPa}$ from June 1996 to June 1997

Fig. 9. CMIP5 historical daily zonally averaged zonal winds at $60^{\circ} \mathrm{N}$ and $10 \mathrm{hPa}$ from 1995-2005 .36

Fig. 10. RCP 4.5 daily zonally averaged zonal winds at $60^{\circ} \mathrm{N}$ and $10 \mathrm{hPa}$ from 2046-2056

Fig. 11. Average number of SSW events per winter for each model, ensemble member, and scenario 


\section{LIST OF ABBREVIATIONS}

AR4

AR5

$\mathrm{AO}$

CanESM2

CMIP

CMIP5

ERA-Interim

IPCC

IPSL-CM5A-LR

MIROC5

MPI-ESM-LR

NAO

NCEP/NCAR

$\mathrm{RCP}$

SSW

WMO
IPCC Fourth Assessment

IPCC Fifth Assessment

Arctic Oscillation

Canadian Centre for Climate Modelling and Analysis

Coupled Model Intercomparison Project

Coupled Model Intercomparison Project phase 5

European Centre for Medium-Range Weather Forecasts Re-Analysis

Intergovernmental Panel on Climate Change

Institut Pierre-Simon Laplace

Atmosphere and Ocean Research Institute, National Institute for Environmental Studies, and Japan Agency for Marine-Earth Science and Technology

Max Planck Institute for Meteorology

North Atlantic Oscillation

National Center for Environmental Prediction and National Center for Atmospheric Research

Representative Concentration Pathway

Sudden Stratospheric Warming

World Meteorological Organization 


\section{Introduction}

Sudden stratospheric warming (SSW) events are a key feature in the northern winter stratosphere and have been shown to have significant impacts on the lower troposphere through cold air outbreaks and altered storm tracks. Following a particularly strong SSW event onset, a cold air outbreak was observed during the winter of 2013/2014 in which temperatures were well below average and surged as far south as Florida, destroying crops and affecting human health (Screen et al. 2015).

It is observed that during major SSW events, there is a reversal of the mean zonal winds from westerlies to easterlies in the stratosphere. During a period of less than one week, temperatures may rapidly increase in the stratosphere by as much as $40 \mathrm{~K}$ (Limpasuvan et al. 2004). To ensure the stratosphere is disturbed by anomalous Rossby wave activity, the reversal of the mean zonal winds is the most effective way to identify a SSW event (Butler et al. 2015).

While much research has been conducted since the discovery of SSW events in the 1950s (Scherhag 1952), researchers have primarily focused on the dynamics and characteristics that define each occurrence in an effort to improve operational forecasting (Limpasuvan et al. 2004; Polvani and Waugh 2004; Charlton and Polvani 2007; Waugh and Polvani 2010; Blume et al. 2012). Although understanding the defining characteristics of SSW events is undoubtedly important, the frequency with which they occur is an ever more pressing issue. As the global climate is expected to continue changing, many factors that are believed to influence the onset of a SSW event are expected to be affected, which could impact the frequency of these events. Increased 
frequency of SSW events could lead to a greater number of cold air outbreaks over North America, ultimately affecting human health and agriculture (Vihma 2014). Although SSW events have been studied extensively, many uncertainties remain and will be discussed below.

Through stratospheric-tropospheric coupling, SSW events originating as high as 10 $\mathrm{hPa}$ are able to be transported downward to the surface, impacting surface weather. Coupling is observed to occur primarily in the northern hemisphere from winter through early spring when the polar night jet is most variable. Since a weakening of the polar vortex is associated with an equatorward shift of the extratropical jet stream, the polar vortex may be well characterized by the annular mode patterns (Gerber and Polvani 2009).

Previous research has indicated the primary driving mechanisms of SSW events are a deceleration of the upper-level jet stream, anomalous Rossby wave activity, and an increasing equator to pole temperature gradient which enhances meandering of the jet stream (Matsuno 1971; Schoeberl 1978; McGuirk and Douglas 1988). In addition, the influence of the Arctic Ocean as a driving mechanism must not be overlooked. Since SSW events occur directly over the North Pole and the stratosphere is intimately coupled with the troposphere, ocean-atmosphere dynamics may have a major role in defining the magnitude and frequency of SSW events (O’Callaghan et al. 2014).

Historically, a thick layer of ice almost completely covers the Arctic Ocean during the winter months. As the temperatures warm during the summer season, the ice melts and reaches its lowest sea ice extent in September (Vihma 2014). As the Earth is expected to 
continue warming in the future, a full recovery of Arctic sea ice during winter is not likely as a result of increased melting. Previous research indicates that the influence of the declining Arctic sea ice trends on the frequency of SSW events remains unclear (Jaiser et al. 2013; Barnes and Polvani 2015; Screen et al. 2015; Overland et al. 2015).

The Coupled Model Intercomparison Project (CMIP) was created in 1995 as a framework and analog to the Atmospheric Model Intercomparison Project for global coupled ocean-atmosphere general circulation models. Since the CMIP project began, there have been many phases; the most recently completed is the fifth phase of the CMIP (CMIP5) (Taylor et al. 2012; Lee and Black 2015). Within the CMIP5, there are 27 available climate models; however, only 4 had data that fulfilled the data requirements of this study.

This study aims to investigate how SSW events will change over the next century. Using CMIP5 climate model data, this study aims to answer the following research questions: (a) How well can SSW events be resolved in climate models compared to National Center for Environmental Prediction and National Center for Atmospheric Research (NCEP/NCAR) reanalysis data from 1950-2005? and (b) How will climate change impact the frequency of SSW events from 2005-2100? To the best of our knowledge, it remains unclear how the stratospheric circulation will be influenced by changes in the meridional temperature gradient. 


\section{Background}

a. Defining sudden stratospheric warming events

A SSW event is an abrupt disturbance of the stratospheric circulation which can rapidly break down the northern hemisphere's polar vortex. Triggered by anomalous vertically propagating Rossby waves, these events are characterized by a rapid increase of the polar stratospheric temperatures, and a reversal of the mean zonal winds poleward of $60^{\circ} \mathrm{N}$. The lifetime of each event varies, but the evolution of a single event can last anywhere from a few days to a few months (Limpasuvan et al. 2004; Charlton \& Polvani 2007). In the literature, there have been a number of ways to characterize SSW events but the reversal of the mean zonal winds and a rapid temperature increase are consistently used for identification (Butler et al. 2015).

Since the 1950s extensive research has examined and sought to characterize the impacts of SSW events but, with such an unpredictable nature, there is still much that is unknown, making it difficult to forecast the onset of an event. Limpasuvan et al. (2004) determined that a SSW event has three dynamically different stages, which can be identified as the precursor, onset, and decay stage. The precursor stage serves to precondition the atmosphere and create an ideal environment for the development and evolution of a SSW event. The most widely recognized precursors include Eurasian snow cover, blocking patterns in the Atlantic and Pacific basins, and stratospheric-tropospheric coupling (Cohen and Jones 2011).

Following the precursor stage, the onset is marked by anomalously weak zonal flow equatorward of $60^{\circ} \mathrm{N}$, but anomalously strong flow poleward of $70^{\circ} \mathrm{N}$. As a result, the 
polar vortex is constricted about the North Pole. During the onset stage, the stratosphere is disturbed and marked by heat flux anomalies above $100 \mathrm{hPa}$ as a result of increased vertically propagating wave activity. These vertically propagating waves produce a drag force on the zonal winds, thus slowing the winds down. Associated with the slowing of the zonal winds and heat flux anomalies, there is a weakening of the polar vortex. With a strong polar vortex, there is notably less wave activity, thus, there are fewer waves which are able to propagate upward into the stratosphere. When there is a strong polar vortex, the heat flux anomalies are still present but are not as significant to the frequency of SSW events (Polvani and Waugh 2004). Limpasuvan et al. (2004) claimed the onset stage is accompanied by equatorward motions in the upper troposphere, rising motions in the middle troposphere, and poleward motions near the surface.

To complete an evolution, the decay stage is the recovery of the polar vortex. During this stage, the zonal wind and temperature anomalies have weakened, allowing the zonal winds to return to a westerly direction and the warm temperature anomalies to descend to $200 \mathrm{hPa}$. In some cases, a final warming may follow the decay stage. This is typically observed as the final collapse of the polar vortex in the spring. A final warming is identified by a slow seasonal recovery of the zonal winds from wintertime westerlies to summertime easterlies. As a result of this slow seasonal recovery, when the polar vortex breaks down in the spring, it is unable to rebuild itself until the following fall (Limpasuvan et al. 2004).

Hemispheric differences in the polar vortices cause differences in wave generation and propagation. The Antarctic vortex is larger with stronger westerlies, and has a longer 
lifespan than its Arctic counterpart. The Antarctic vortex is also much colder with a narrow range of seasonal variability. The larger topography and land-sea contrasts in the northern hemisphere excite more planetary-scale Rossby waves that disturb the polar vortex more than in the southern hemisphere (Waugh and Polvani 2010). As a result, SSW events are commonly observed in the northern hemisphere and very few are observed in the southern hemisphere. Presently, the only event in the southern hemisphere mentioned in literature occurred in 2002 (Esler et al. 2006).

SSW events can be classified into two types of events, vortex displacement and vortex split. During a vortex displacement, the polar vortex is displaced off the center axis (Fig. 1a). A vortex split occurs when the polar vortex is separated into two fragments of comparable size (Fig. 1b). Vortex displacements have a tendency to have half the magnitude of a vortex split (O’Callaghan et al. 2014). While both types of events occur during zonal wavenumber-1 and wavenumber-2 Rossby wave patterns, vortex displacements are more commonly observed during zonal wavenumber-1 patterns. In contrast, vortex splits are associated with zonal wavenumber-2 patterns (Bridger and Stevens 1981; Charlton and Polvani 2007; Bancala et al. 2012). 
a)

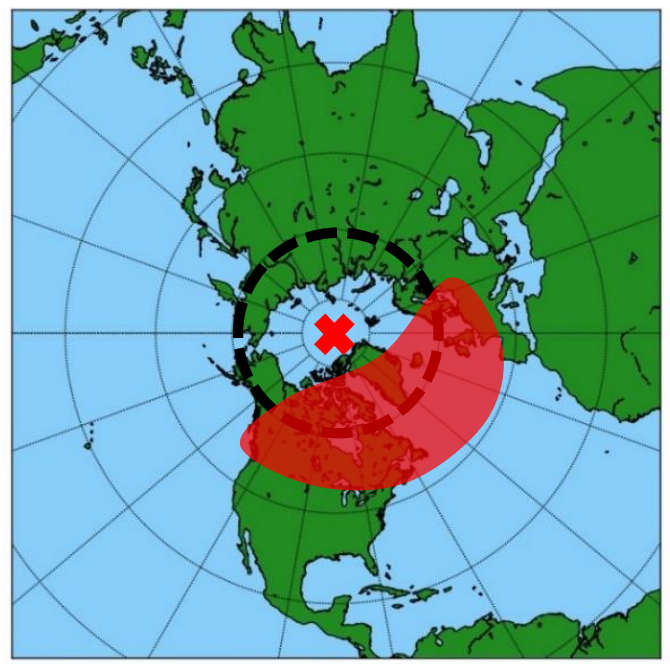

b)

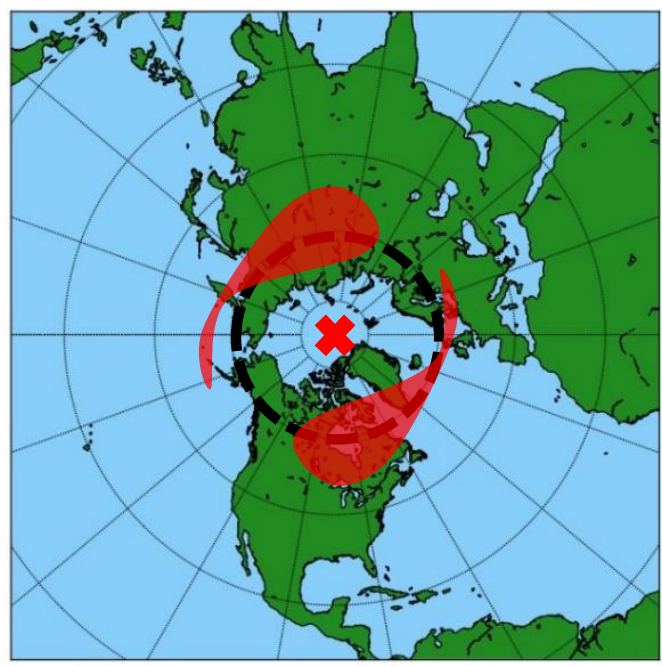

FIG. 1. Conceptual model of a north polar stereographic projection showing a vortex displacement event (a) and a vortex split event (b) at $10 \mathrm{hPa}$. Red shading represents potential vorticity. The ' $\mathrm{X}$ ' represents the center axis and the thick dotted line represents the average outer edge of the polar vortex. Latitudinal parallels are every $20^{\circ}$ beginning at $80^{\circ} \mathrm{N}$ and longitudinal meridinals are every $20^{\circ}$.

Located over the northern pole, SSW events occur over a large body of water, the Arctic Ocean. Therefore, careful consideration of the effects of the Arctic Ocean on the atmosphere is needed. O'Callaghan et al. (2014) considered the effects of oceanatmosphere coupling on the dynamics of each type of SSW event. Through surface wind stress anomalies, anomalous Ekman heat fluxes are generated which provide a clear channel for the ocean and atmosphere to interact. If strong enough, the heat fluxes can influence the evolution of a vortex split event. Since vortex displacements have a tendency to have half the magnitude of a vortex split, the evolution is not distinctly affected by strong Ekman heat fluxes. The Ekman heat fluxes can influence the evolution of vortex split events following the onset of an event by modifying the mixed layer heat budget (O'Callaghan et al. 2014). Further insight is required to understand the 
propagation of the heat flux anomalies within the ocean and how this may impact oceanatmosphere coupling in the future.

To develop a greater understanding of SSW event frequency, Blume et al. (2012) used supervised learning and linear discriminant analysis to statistically analyze SSW events. Using 40 years of European Centre for Medium-Range Weather Forecasts ReAnalysis (ERA-interim) and NCEP/NCAR reanalysis data from 1958-2010, they found SSW events were observed approximately once every two years. While the intensity and type of event varied significantly, they determined that the greatest number and the most severe events occur during January, with fewer observed in December and February. During some years, events were observed as late as March. These later events are considered to be separate from the major events and are referred as "stratospheric final warmings".

\section{b. Stratospheric-tropospheric coupling}

For much of the year, the stratosphere over the North Pole is inherently stable. However, during the winter season, the stratospheric circulation is most variable, as shown in Fig. 2 from 1 June 1995 to 1 June 1996. When the zonally averaged zonal winds are negative (positive), the zonal winds are easterly (westerly). During the winter, the polar vortex is disturbed by planetary-scale Rossby waves and the polar vortex may vary in strength. 


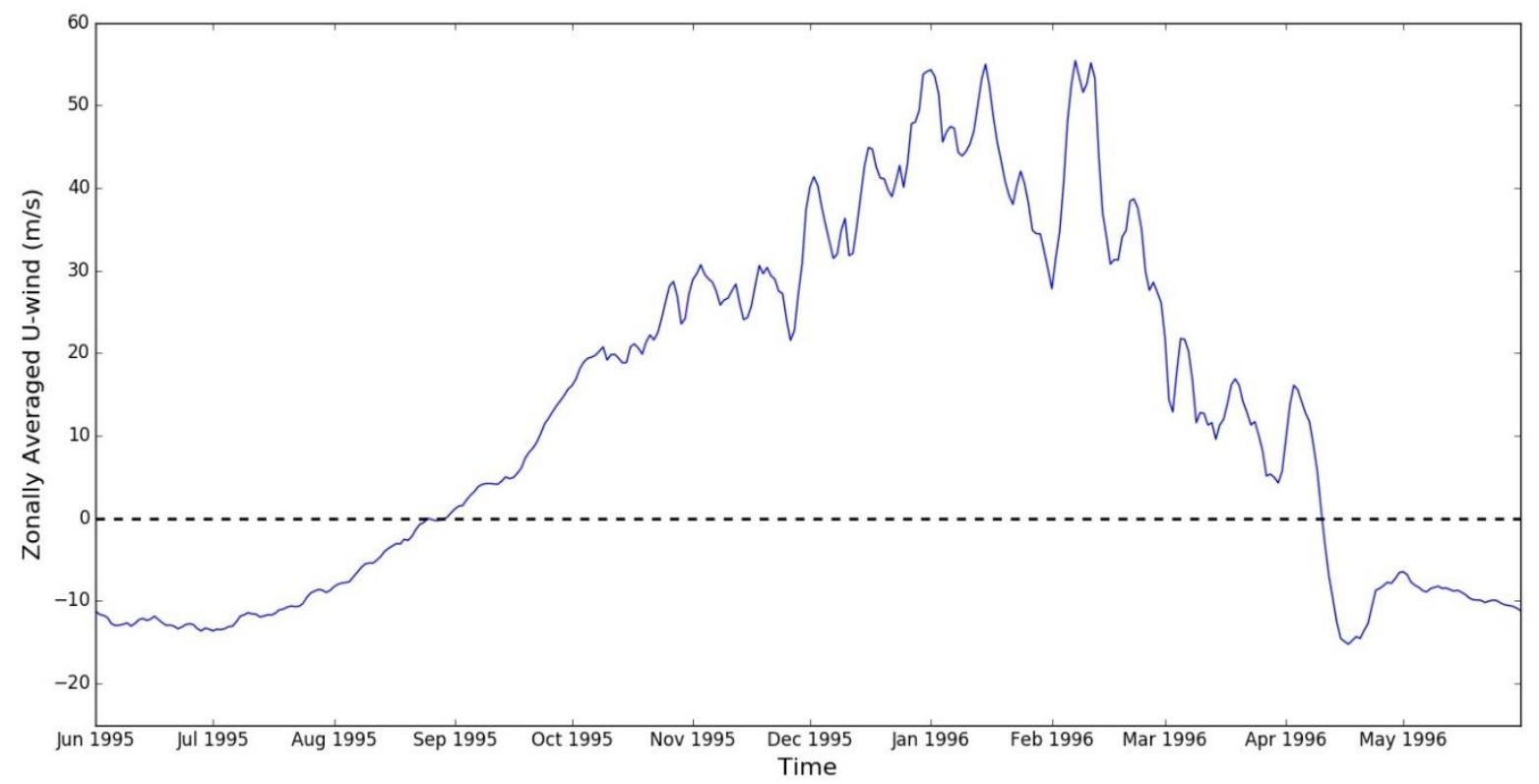

FIG. 2. Daily zonally averaged zonal winds at $60^{\circ} \mathrm{N}$ and $10 \mathrm{hPa}$ in NCEP/NCAR reanalysis data from 1 June 1995 to 1 June 1996.

Originating mostly in the troposphere, westward angular momentum is transported upward, allowing it to interact with the stratospheric flow. Here, the zonally averaged eastward wind $(\bar{u})$ is able to influence the refraction of upward propagating waves, alter the locations where the angular momentum is changed, and initiate a positive feedback in which the waves penetrate the troposphere as the eastward wind anomalies descend toward the surface (Baldwin and Dunkerton 2001). This atmospheric relationship is better known as stratospheric-tropospheric coupling.

The upward flux of energy is believed to occur up to 60 days prior to a warming event, and is viewed as a precursor to SSW events allowing the atmosphere to be preconditioned. This creates a convergence of the Eliassen-Palm flux which initializes the wave-induced deceleration of the polar night jet (Limpasuvan et al. 2004; Taguchi 2008). The Eliassen-Palm flux is an important tool used to quantify small-amplitude waves, 
describe wave propagation in mean zonal shear flows, and quantify the effective mean zonal force induced by the waves. In addition to being a precursor to SSW events, stratospheric-tropospheric coupling has been linked to anomalous values with teleconnections such as the Northern Atlantic Oscillation (NAO) and the Arctic Oscillation (AO) (Baldwin and Dunkerton 2001; Polvani and Waugh 2004; Shaw and Perlwitz 2013).

Limpasuvan et al. (2004) found that the key dynamical processes underlying the observed stratospheric-tropospheric coupling are between variability in the zonal flow of the lower stratosphere and wave activity in the troposphere. Through composite analysis Shaw and Perlwitz (2013) examined the life cycle of northern hemispheric downward wave coupling. The results illustrated that downward wave coupling from the stratosphere to the troposphere involves changes in the basic state of the stratosphere and of wavenumber-1 Rossby wave patterns. The event starts with a positive heat flux in the stratosphere and a wavenumber-1 pattern which indicates upward wave coupling (exhibits a westward phase tilt). Conducive to the upward wave propagation, there is a weakening of the polar vortex in the upper stratosphere which produces a region of negative vertical zonal wind shear. This acts as a vertical reflecting surface, causing the wavenumber-1 pattern to then exhibit an eastward phase tilt. This change in phase tilt indicates wave reflection and downward wave coupling.

Stratospheric-Tropospheric coupling is of utmost importance to the transport of energy and momentum between the stratosphere and troposphere. As a result of this intimate relationship, SSW events are able to influence surface weather regimes (Gerber 
and Polvani 2009). Through further understanding of this connection we can improve predictability of SSW events and our understanding of the effects they have on tropospheric weather such as blocking events and storm tracks.

\section{c. Tropospheric impacts}

In the troposphere, weather patterns can change rapidly over a period of only a few days. As a result, numerical weather prediction models are likely to incorrectly forecast past a week. In many regions around the world, studying teleconnections such as the El Niño/Southern Oscillation, AO, and NAO can help increase the odds of creating a reliable long-range weather outlook. Although the stratospheric circulation has previously been regarded as having little influence on surface weather, Baldwin and Dunkerton (2001) have shown that large stratospheric circulation anomalies occasionally reach the Earth's surface causing anomalous weather regimes.

SSW events affect surface weather through the amplification of the jet stream over the midlatitudes. The amplification of the jet stream is caused by slower Rossby wave propagation, making the jet stream appear "wavier" increasing the meridional wave amplitude of the jet stream. As a result of this amplification, cold air anomalies are observed over eastern North America and Europe, and warm air anomalies are observed over western North America (McGuirk and Douglas 1988). This can have significant impacts on the economy and agriculture such as those seen during the winter of 2013/2014 (Screen et al. 2015). During the winter of 2013/2014 several cold temperature anomalies surged equatorward over the eastern United States and Midwest causing heavy snowfall and record breaking low temperatures. The temperatures were recorded $20^{\circ} \mathrm{C}$ 
cooler in most locations than the 20 year climatological average. Transportation was disrupted by heavy snowfall, and agricultural crops were destroyed by freezing temperatures that were observed as far south as Florida (Screen et al. 2015). Although this is a single extreme winter weather event, as amplification is expected to persist, the frequency of such extreme winter weather events remains an active area of research (Barnes and Polvani 2015).

Due to the meridional amplification of the jet stream in the midlatitudes, cyclogenesis can be affected through slower storm propagation and altered storm tracks (McGuirk and Douglas 1988). Storm tracks are altered following a more southerly track and having a sharper eastward curve inland once off the eastern coast of the United States. In addition, low pressure systems which commonly develop east of the Rocky Mountains in Colorado, all but disappear when there is an amplified jet stream (McGuirk and Douglas 1988). Blocking patterns have also been associated with these events and are considered an effective precursor occurring up to 60 days prior to an event. However, it is not a viable solution to assume a particular blocking pattern will always result in the occurrence of a SSW event as it is only one possible mechanism (McGuirk and Douglas 1988; Bancala et al. 2012).

Predicting the onset of a SSW event can be very troublesome for an operational forecaster. Annular modes of variability are known to increase predictability of SSW events since variations in the strength of the polar vortex are well characterized. These modes of variability are recognized by synchronous fluctuations in pressure of opposing signs between the higher and lower latitudes (Baldwin and Dunkerton 2001). Sometimes 
acting independent of each other, strong anomalies of the stratospheric annular mode appear just above the tropopause with anomalies in the troposphere of the same sign. Differentiating by region, two annular modes frequently researched in relation to stratospheric phenomena are the AO and NAO. Baldwin and Dunkerton (2001) found that when these annular modes are negative, the polar vortex is weak. During a positive phase, the polar vortex is strong. A weak polar vortex promotes an ideal environment for external forcing to disrupt the stratospheric circulation and increase the likelihood of a SSW event.

\section{d. Relationship to Arctic sea ice}

SSW events can significantly impact the northern hemisphere during winter, therefore, it is necessary to consider the Arctic Ocean as it may have the greatest influence on the occurrence, intensity, and frequency of such an event. During the winter months, the cold surface temperatures over the Arctic Ocean allow ice to form and completely cover the ocean. During the summer months when temperatures increase, the sea ice volume decreases, and the greatest loss is observed in September.

Sea ice is extremely important to the surface energy budget because it regulates the surface heat fluxes from surface albedo (Peings and Magnusdottir 2013). Unfortunately, in recent decades the Arctic has experienced significant changes in temperature, resulting in the loss of two-thirds of its sea ice volume over a 30 year time period (Overland et al. 2015). This means that after the sea ice is at its lowest volume in September, it is unable to fully recover and refreeze as extensively as it once had. This is increasingly important in winter, when the thermal difference between sea ice and open water is largest (Vihma 
2014). In Fig. 3, the Arctic sea ice extent for September 2016 and the climatological sea ice extent from 1981-2010 illustrate how much sea ice has melted and not been able to fully recover in recent years. Arctic sea ice loss can result in greater variability and heightened environmental conditions over the Arctic (Cai et al. 2012).

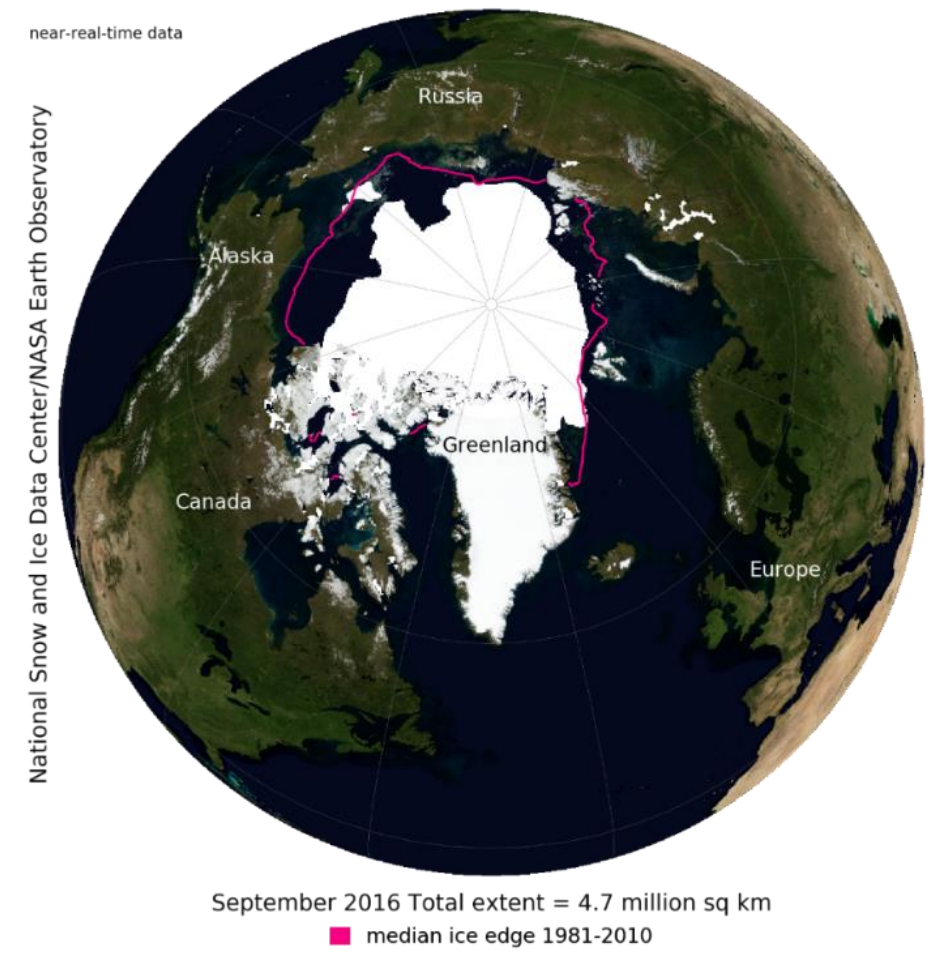

FIG. 3. Arctic sea ice extent for September 2016 (white area) compared with the median ice edge (pink line) from 1981-2010. Image courtesy of the National Snow and Ice Data Center, University of Colorado, Boulder.

Surface temperatures are rising two to four times faster in the Arctic than the global average. This phenomenon, better known as Arctic amplification, can help describe the heightened sensitivity of the Arctic climate due to rapid temperature changes (Screen et al. 2012). Arctic amplification is the result of positive feedback mechanisms and increased anthropogenic forcings. The response of the jet stream to this new environment 
is still uncertain but it is believed that as warming conditions persist, leading to a possible ice-free Arctic, the jet stream will become more meridionally amplified (Cai et al. 2012; Overland et al. 2015). This can increase the occurrence of blocking patterns and lead to an increase in severe weather events. However, the changes resulting from Arctic amplification are difficult to quantify with such a significant amount of natural variability during the winter months (Overland et al. 2015). It is suggested that atmospheric internal variability could be masking the stratospheric responses to sea ice loss (Screen et al. 2013).

Vihma (2014) addressed the local and remote effects of the sea ice decline on weather and climate. It is evident that the reduced sea ice cover has caused an increase in the heat flux from the ocean to the atmosphere in autumn and early winter. Locally, as a result of an increased heat flux, increases in air temperature, moisture, and cloud cover have been observed in recent years. There has also been a decrease in static stability near the surface (Vihma 2014). While it is widely recognized that regional impacts due to Arctic sea ice loss will vary, Screen et al. (2015) addressed the possibility that as sea ice loss intensifies, there will be a decreased duration of cold temperature anomalies over the high latitudes and across the central and eastern United States. Across central Asia there will likely be an increased duration of cold temperature anomalies. In addition, there will be more extreme precipitation events with a reduction in drought across the high latitudes.

Using the fifth Community Atmospheric Model, Peings and Magnusdottir (2013) were able to support these claims based on the role of sea ice forcing on the atmospheric circulation. A weak but significant change in the meridional amplitude of the midlatitude 
planetary waves was found, and cold anomalies did not increase. These results are believed to be caused by the large lower-tropospheric warming that was found to extend well beyond the Arctic and prevent the occurrence of cold anomalies. Further research is needed to account for the net effects of greenhouse gas concentrations on sea ice as both studies were limited by not including these effects. It is suggested that by including the greenhouse gas effects, the response of the atmosphere will be amplified and could lead to fewer cold anomalies.

Cai et al. (2012) recognized the possible implications of an ice-free Arctic and examined how this might affect the stratosphere. Through the impacts observed most recently in the $\mathrm{AO}$, the $\mathrm{AO}$ is in a predominant neutral phase with decreased sea ice volume. This creates a favorable environment for the onset of a SSW event because when the AO trends negative, the zonal winds slow down and the polar vortex is easily disturbed.

While many mechanisms have been linked to the occurrence of SSW events, few have examined the effects of sea ice loss on SSW events. Deser et al. (2014) used the Coupled Climate System Model version 4 to investigate the role of ocean-atmospheric coupling in the global response to sea ice loss. By not considering ocean coupling, the response to sea ice loss is confined to the midlatitudes where there is a weakening and equatorward shift of the westerlies. When ocean coupling is included, there is a global response to Arctic sea ice loss. Therefore, ocean dynamics are a fundamental component in considering the impacts of sea ice loss on SSW events. Deser et al. (2014) also showed that heat flux responses of the Arctic Ocean peak during the months when SSW events 
are most frequently observed. This implies a direct relationship between ocean dy namics and the occurrence of SSW events.

\section{e. Impact of climate change on SSW}

Increasing greenhouse gas concentrations over the $21^{\text {st }}$ century are projected to cause significant changes to the global climate at all latitudes, altitudes, and scales (Stocker et al. 2013). For example, the surface air temperature has increased across almost all weather stations north of $60^{\circ} \mathrm{N}$, with the greatest increases observed in coastal regions surrounding the Arctic Ocean (Vihma 2014). Using the CMIP5 to determine how the Arctic will respond to a changed environment in the future, Barnes and Polvani (2015) found that of the 27 CMIP5 models available, every model showed enhanced Arctic warming by the end of the $21^{\text {st }}$ century. However, it is unlikely that Arctic warming will be the sole cause of changes to the midlatitude circulation. It is projected that the lowertropospheric meridional temperature gradient will decrease while the upper-tropospheric meridional temperature gradient increases. As a result, it is unclear which change in the temperature gradient the midlatitude circulation will ultimately respond to (Barnes and Polvani 2015). This is extremely important when considering the effects this may have on global temperature distribution, wave generation, and the frequency of SSW events.

As a result of reduced insulation from loss of sea ice, the ocean will lose more heat to the atmosphere. This is significant since the heat capacity of a unit volume of the ocean is approximately 3,600 times greater than that of air. It is expected that during the winter season, temperature changes will be much easier to detect in the atmosphere than the ocean due to the large heat flux from the ocean (Vihma 2014). The changes observed in 
the heat flux from the ocean to the atmosphere has been attributed to reduced vertical static stability. Reduced vertical static stability increases baroclinic instability and can therefore modulate nonlinear interactions between baroclinic wave energy fluxes in a period of 2.5 to 6 days (Jaiser et al. 2013). Changes in heat flux have also been related to increased water vapor content during the winter months. As a result, Overland and Wang (2010) found increased surface air temperature anomalies upwards of $3^{\circ} \mathrm{C}$ and midtropospheric air temperature anomalies of $1^{\circ} \mathrm{C}$. These temperature anomalies have been associated with an increased 1000-500 hPa atmospheric thickness every year there has been significantly reduced arctic sea ice.

Due to the increased temperature anomalies a decrease has been observed in the meridional 1000-500 $\mathrm{hPa}$ thickness, which according to the thermal wind relationship reduces the zonal wind speed in the mid-troposphere (Vihma 2014). Since the zonal wind is considered one of the main driving mechanisms of SSW events, it is likely that a reduced meridional 1000-500 $\mathrm{hPa}$ thickness gradient would increase the frequency of SSW events in the future. This would likely cause an increase in the frequency of SSW events because the slower zonal winds would enhance planetary wave activity by increasing their amplitude and slow the eastward propagation of these waves. Further research should be conducted since it is not clear if any significant changes in the wave amplitude and phase speed have been found thus far. 


\section{Methodology}

\section{a. Reanalysis data}

The NCEP/NCAR Reanalysis project uses a frozen state-of-the-art global data assimilation system to produce a global record which can be used for analysis of a multitude of atmospheric variables in order to advance current research in climate monitoring communities. The project involves the use of land surface, ship, rawinsonde, pilot balloon, aircraft, satellite, and other data to conduct quality control and to assimilate data. In essence, reanalysis data are an observationally derived dataset that is placed on an evenly spaced grid, allowing multiple measurements to be compared easily. This creates a dynamically continuous estimate of the state of the climate at each time step (Kalnay et al. 1996). When the reanalysis project was first published (Kalnay et al. 1996) it was only a 40-year record (1957-1996). Since this initial publishing, the record has been extended to include data from 1948 to the present day. As the reanalysis data is based on observations and has available climate data for the entire duration of this study, it serves as an ideal reference to compare with the historical CMIP5 multi-model results.

Previous studies used NCEP/NCAR reanalysis data to effectively identify and characterize SSW events. Using 44 years of NCEP/NCAR reanalysis data from 19582001, Limpasuvan et al. (2004) analyzed 39 SSW events in an effort to study the evolution of atmospheric flow and wave fluxes throughout the life cycle of each SSW event. This analysis identified that SSW events can be described in three distinct stages known as the precursor, onset, and decay. Charlton and Polvani (2007) used NCEP/NCAR reanalysis data from 1958-2002 to create a climatology of all SSW events 
between November and March. In their analysis, 27 SSW events were identified with an average of $0.60 \mathrm{SSW}$ events per winter. In creating a complete climatology, SSW events were also classified by event type (vortex split or vortex displacement). Blume et al. (2012) used NCEP/NCAR reanalysis data from 1958-2010 and nonlinear statistical methods to classify SSW events. It was found that using nonlinear statistical methods greatly improved the ability to classify SSW events compared to linear statistical methods (Blume et al. 2012). Most recently, Butler et al. (2015) used NCEP/NCAR reanalysis data to review the most widely used definitions of SSW events to determine the most effective way to identify and classify SSW events in numerical modelling. The authors found that the most effective definition of a SSW event depended entirely on the type of study being conducted. Studies that examine stratospheric-tropospheric coupling require different diagnostics compared to applications such as forecasting SSW frequency. In addition, O'Callaghan et al. (2014) used NCEP/NCAR reanalysis data to examine the effects of different SSW event types on the ocean. The results of these studies show that NCEP/NCAR reanalysis data can be used to effectively study SSW events.

As with global climate models, atmospheric reanalyses include errors and biases, especially in the boundary layer. During the spring and summer, all reanalyses have large errors in the vertical profiles of temperature and relative humidity. Some, such as the ERA-Interim, have a warm bias of $2^{\circ} \mathrm{C}$ or more in the lowest 400 meters (Vihma 2014). Sea-level pressure seems to be captured more accurately across different reanalyses models. For example, the ERA-Interim and NCEP/NCAR agree well on the timing and location of cyclones over the Arctic. Successes in this agreement can be attributed to the 
buoy network maintained by the International Arctic Buoy Program. Unfortunately, due to a decrease in sea ice cover, larger gaps are being found between buoys, decreasing the accuracy of weather forecasts over the Arctic (Vihma 2014). According to Vihma (2014) errors have ultimately been found at the surface, in the boundary layer, and when examining cloud and precipitation variables with reanalysis data. Atmospheric models are known to have major problems with moisture variables in the Arctic, estimating annual net precipitation $60 \%$ lower than the water vapor flux convergence. A large moist bias of $0.3-0.5 \mathrm{~g} \mathrm{~kg}^{-1}$ is also found throughout the lowermost $1 \mathrm{~km}$ over the Arctic sea ice (Jakobson et al. 2012). This does not mean that reanalysis data cannot be used reliably to analyze historical atmospheric conditions over the Arctic, but it is recommended that caution be taken to account for any uncertainties and biases the data may have.

To quantify the occurrence of a SSW event, NCEP/NCAR reanalysis 1 daily zonal wind data at $10 \mathrm{hPa}$ are examined historically from 1950-2005. Since SSW events occur in the middle to upper stratosphere, it is useful to analyze the events at $10 \mathrm{hPa}$. The NCEP/NCAR reanalysis 1 data had a globally gridded spatial resolution of $2.5^{\circ} \times 2.5^{\circ}$ and was provided by NOAA/OAR/ESRL PSD, Boulder, Colorado, USA, available at http://www.esrl.noaa.gov/psd/. This data was used to verify our algorithm can correctly identify a SSW event in the historical datasets.

\section{b. Climate models}

To assess the relationship of SSW event frequency and climate change, CMIP5 multimodel data are used (Taylor et al. 2012). Superseding previous phases of the CMIP such as the highly successful phase 3 of CMIP, the CMIP5 contains more metadata describing 
model simulations than previous phases. The CMIP5 also includes a greater number of experiments, allowing a wider variety of scientific questions to be answered. Higher resolution models and more archived output variables are also available in the CMIP5, allowing improved climate research results such as those observed in the Intergovernmental Panel on Climate Change (IPCC) Fourth Assessment (AR4) and IPCC Fifth Assessment (AR5) (Stouffer et al. 2011).

Research that has been conducted using the CMIP5 has shown that the high-top models resolve SSW events most effectively because they resolve data up to $0.1 \mathrm{hPa}$ (Charlton-Perez et al. 2013). Low-top models do not resolve these events effectively because their model top is generally below the stratopause (Charlton-Perez et al. 2013). When using the CMIP5 to analyze stratospheric variability, there may be some overrepresentation with high-top models. In contrast, low-top models within CMIP5 underestimate the stratospheric variability (Lee and Black 2015).

Using four models, out of 27 available models within the CMIP5, historical simulations of daily mean zonal wind data were analyzed at $10 \mathrm{hPa}$ for 56 years from 1950-2005. The four models and information regarding their spatial resolution, lid top, and number of vertical levels are found in Table 1. 
TABLE 1. List of all CMIP5 models used in this study and their specific properties of atmospheric resolution, lid top, and number of vertical levels found within the model (data adapted from Manzini et al. 2014).

\begin{tabular}{|c|c|c|c|c|}
\hline Institute/Model Group & Model Name & $\begin{array}{l}\text { Atmospheric } \\
\text { Resolution }\end{array}$ & $\begin{array}{l}\text { Lid } \\
\text { Top }\end{array}$ & $\begin{array}{l}\text { Vertical } \\
\text { Levels }\end{array}$ \\
\hline $\begin{array}{c}\text { Canadian Centre for Climate } \\
\text { Modelling and Analysis }\end{array}$ & CanESM2 & $2.79^{\circ} \times 2.81^{\circ}$ & $1 \mathrm{hPa}$ & 35 \\
\hline Institut Pierre-Simon Laplace & IPSL-CM5A-LR & $1.89^{\circ} \times 3.75^{\circ}$ & $\begin{array}{l}0.04 \\
\mathrm{hPa}\end{array}$ & 39 \\
\hline $\begin{array}{c}\text { Atmosphere and Ocean } \\
\text { Research Institute, National } \\
\text { Institute for Environmental } \\
\text { Studies, and Japan Agency } \\
\text { for Marine-Earth Science } \\
\text { and Technology }\end{array}$ & MIROC5 & $1.4^{\circ} \times 1.4^{\circ}$ & $3 \mathrm{hPa}$ & 56 \\
\hline $\begin{array}{l}\text { Max Planck Institute for } \\
\text { Meteorology }\end{array}$ & MPI-ESM-LR & $1.87^{\circ} \times 1.87^{\circ}$ & $\begin{array}{l}0.01 \\
\mathrm{hPa}\end{array}$ & 47 \\
\hline
\end{tabular}

The four models used for this study had complete daily measurements of the zonal wind at $10 \mathrm{hPa}$ from 1950-2005. Secondly, the models were available under the RCP 4.5 and 8.5 emission scenarios from 2006-2100, providing a complete analysis between the historical and projected simulation results. Third, the four models were considered hightop models since their lid tops were well within the stratosphere. This allowed the greatest amount of accuracy in resolving and identifying SSW events. Other high top models were available under CMIP5, but they did not have complete data for the entire study period. Within these four models, three ensemble members were chosen to provide robust results and analyze model sensitivity and verify any uncertainties. The three ensemble members were identified as r1i1p1, r2i1p1, and r3i1p1 where ' $r$ ' is the 
abbreviation for realization, ' $i$ ' is for the initialization method, and ' $p$ ' represents the physics scheme.

CMIP5 models and nearly all current generation models exhibit systematic biases when simulating some of the circulation metrics used to identify SSW events. For example, it is known that most models underestimate North Atlantic blocking frequencies during the cool months and overestimate these frequencies during the warm months. These models also tend to place the jet stream equatorward of its observed position. Although uncertainties exist within the CMIP5 models, these models are still capable of capturing the large-scale dynamics needed to identify SSW events. While the model biases may reduce our confidence in the future projections, it is currently the most effective tool available to predict the behavior of large-scale circulations over the next century (Barnes and Polvani 2015).

Emission scenarios assess how social and economic factors could affect greenhouse gas emissions. These scenarios are used as input for climate model runs in order to calculate possible changes in the future climate and how it may evolve in time (Hibbard et al. 2011). Following the release of the AR4 in 2007, the RCPs were introduced as a set of four emission concentration and land-use trajectories. The RCPs explore possible future pathways for changes in heat trapping gases, weather, and climate. The four RCP emission scenarios identified as 2.6, 4.5, 6.0, and 8.5 reflect the socio-economic pathways which reach a radiative forcing of $2.6,4.5,6.0$, and $8.5 \mathrm{~W} / \mathrm{m}^{2}$ by the end of the $21^{\text {st }}$ century (Hibbard et al. 2011). 
To analyze future climate projections, simulations of the daily mean zonal wind data at $10 \mathrm{hPa}$ were examined for 95 years from 2005-2100 under the RCP scenarios 4.5 and 8.5. Only the RCP 4.5 and 8.5 were used in this study because they had identical model data available as that used in the historical experiments (CanESM2, IPSL-CM5A-LR, MIROC5, and MPI-ESM-LR), and represent the two extremes of what is likely possible future climates. The RCP 4.5 and 8.5 also had the same number of ensemble members (three) available for the zonal wind variable. It is important that the same models and ensemble members were used between the historical and future experiments for accuracy and completeness in this study. To verify the statistical significance of the results found in this study, a student's t-test was conducted in conjunction with both the historical and RCP simulations.

\section{c. Analysis}

To quantify the occurrence of a SSW event in this study, the algorithm by Charlton and Polvani (2007) was used. Using this algorithm, SSW events were objectively identified and characterized based on the mean zonal wind at $60^{\circ} \mathrm{N}$ and $10 \mathrm{hPa}$. This was done to simplify the analysis and derive only the needed variables from the climate models as the datasets were prodigious. For validation purposes, it was important that identification of SSW events be as simple as possible to refrain from introducing unnecessary interpolation and differentiation errors. Since SSW events occur most frequently during the northern hemisphere winter, data was filtered for the months of November through March. Below is a description of how the algorithm works. 
To identify a SSW event, daily zonal winds at $60^{\circ} \mathrm{N}$ and $10 \mathrm{hPa}$ were zonally averaged from 1 November through 31 March. When the winds became easterly during the winter months, an anomalous event was marked. The first day in which the daily mean zonal winds were easterly was defined as the central date (start date) of a SSW event. For the purposes of this study, once an event was identified, no day within 20 consecutive days of the central date could be identified as an additional event. As the zonal winds can fluctuate between westerly and easterly following the onset of an event, this ensured that no event could be counted twice. A schematic of this identification process is found in Fig. 4. Final warmings were not counted in this study; to separate these, cases where the zonal winds did not return to westerly for 10 consecutive days prior to 30 April were counted as final warmings and discarded. 

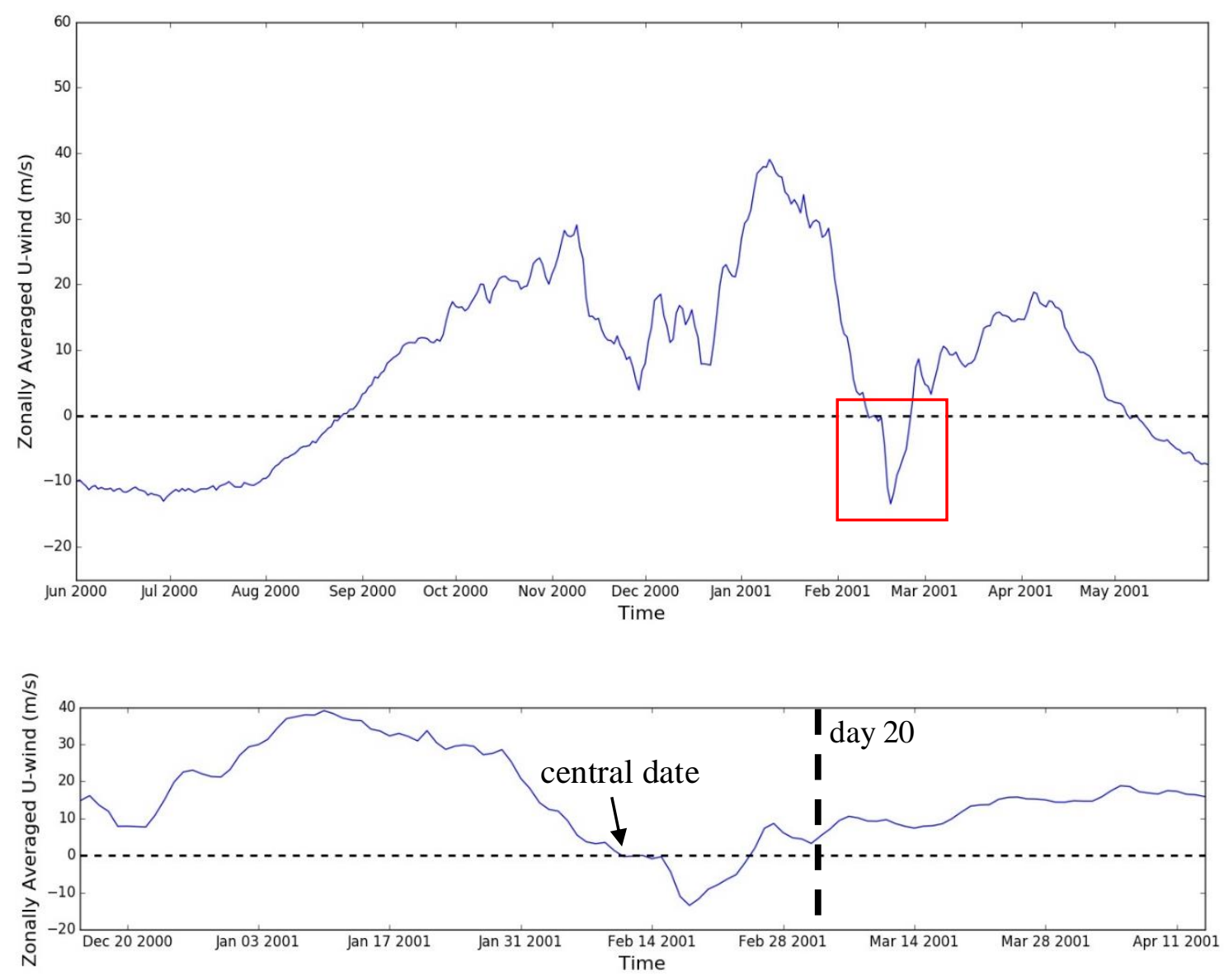

FIG. 4. Schematic model of the process used to identify a SSW event. Daily NCEP/NCAR reanalysis zonally averaged winds at $60^{\circ} \mathrm{N}$ (blue line) are shown from 1 June 2000 to 1 June 2001 (a) and 15 December 2000 to 15 April 2001 (b). The red box highlights a SSW event. The central date is identified as 11 February 2001 and no date within 20 days can be counted as a second event (annotated on graph).

This method closely follows the World Meteorological Organization (WMO) definition of a SSW event. The WMO defines the occurrence of a SSW event as the reversal of the stratospheric circulation during winter at $60^{\circ} \mathrm{N}$ and $10 \mathrm{hPa}$ from westerly to easterly (Andrews et al. 1985). It also requires that the $10 \mathrm{hPa}$ zonal mean temperature between $60^{\circ} \mathrm{N}$ and $90^{\circ} \mathrm{N}$ be positive. Related studies have included this additional constraint (Limpasuvan et al. 2004), however, it was found that by including this 
additional constraint significant value was not added to the algorithm in order to effectively identify a SSW event. As a result, the temperature criterion had been excluded from the algorithm and only the zonally averaged zonal winds were used. Other methods have been used to identify SSW events such as Empirical Orthogonal Functions and $k$ means clustering technique (Baldwin and Dunkerton 2001; Coughlin and Gray 2009). While these have proven to be successful in improving our understanding of SSW events and their impacts, the diagnostics of these methods are more complex and may be better suited when studying stratospheric-tropospheric coupling related to SSW events and not the frequency in which SSW events occur (Butler et al. 2015).

This study differed from that of Charlton and Polvani (2007) in that the number of years used in the historical study were extended from 1958-2002 to 1950-2005. In addition, no classification of the type of SSW event was conducted in this study. The purpose of this study was to determine how effectively the CMIP5 models resolve SSW events in the recent past. Following successful results in the historical experiments, the CMIP5 models were used to determine how the frequency of SSW events may change as a result of a warming climate. Confidence in results was found when the historical frequency of events was similar to that determined in studies such as Butler et al. (2015) and Charlton and Polvani (2007). Although our study extended the historical time period, only a few more events were anticipated to be found. If a model appeared to have poor results compared to observations during the historical period, there was little confidence in those results in the RCP experiments. 


\section{Results}

\section{a. NCEP/NCAR reanalysis}

NCEP/NCAR reanalysis data were used to study SSW events between 1950-2005 using the algorithm by Charlton and Polvani (2007). Figure 5 shows the zonally averaged zonal winds at $60^{\circ} \mathrm{N}$ and $10 \mathrm{hPa}$ from $1950-2005$ in the NCEP/NCAR reanalysis data.

This was done to analyze stratospheric variability and seasonal fluctuation of the stratospheric zonal winds between easterlies and westerlies. The stratospheric zonal winds were also observed to fluctuate within an individual season. This variability within a season occurred most often during the winter season. If the zonal winds changed direction abruptly, this may indicate the start of a SSW event. Figure 5 shows that the westerly zonal winds appear to be strongest during the 1970s and 1980s. This trend could be the result of a stronger polar vortex, lending itself to the stronger westerly winds.

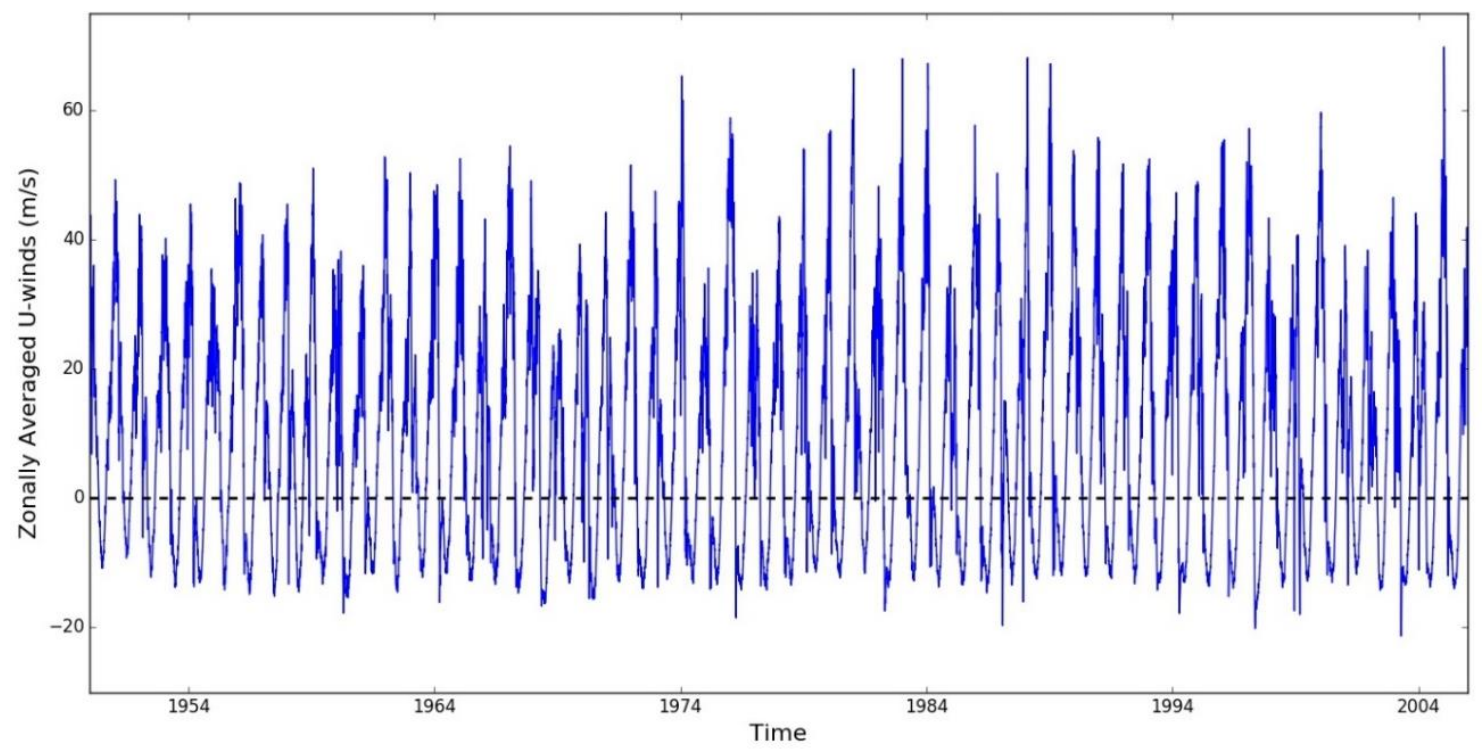

FIG. 5. Daily zonally averaged zonal winds at $60^{\circ} \mathrm{N}$ and $10 \mathrm{hPa}$ from $1950-2005$ using NCEP/NCAR Reanalysis data. 
Figure 6 shows that the zonally averaged zonal winds at $60^{\circ} \mathrm{N}$ and $10 \mathrm{hPa}$ have a distinct seasonal fluctuation between easterly and westerly winds from 1995-2005. It was observed that during the summer season, zonal winds were easterly in the stratosphere and during the winter season they were westerly. When westerly winds were observed, there is an unambiguous irregularity compared to the periods of easterly winds. This instability during the westerly winds could be caused by external forcing from Rossby wave activity. During the northern hemisphere winter months, there is increased Rossby wave activity. In the summer months, there is much less variability because the Rossby waves are unable to propagate within easterly winds (Charney and Drazin 1961).

Abrupt changes in the zonally averaged flow were also distinct. During the years 1998-1999 and 2000-2001, stark changes were observed when the zonal winds were predominantly westerly and suddenly became easterly. A few days later, the zonal winds returned to a westerly flow. In these two particular years, SSW events occurred. The event which occurred during the winter of 2000-2001 is discussed below. 


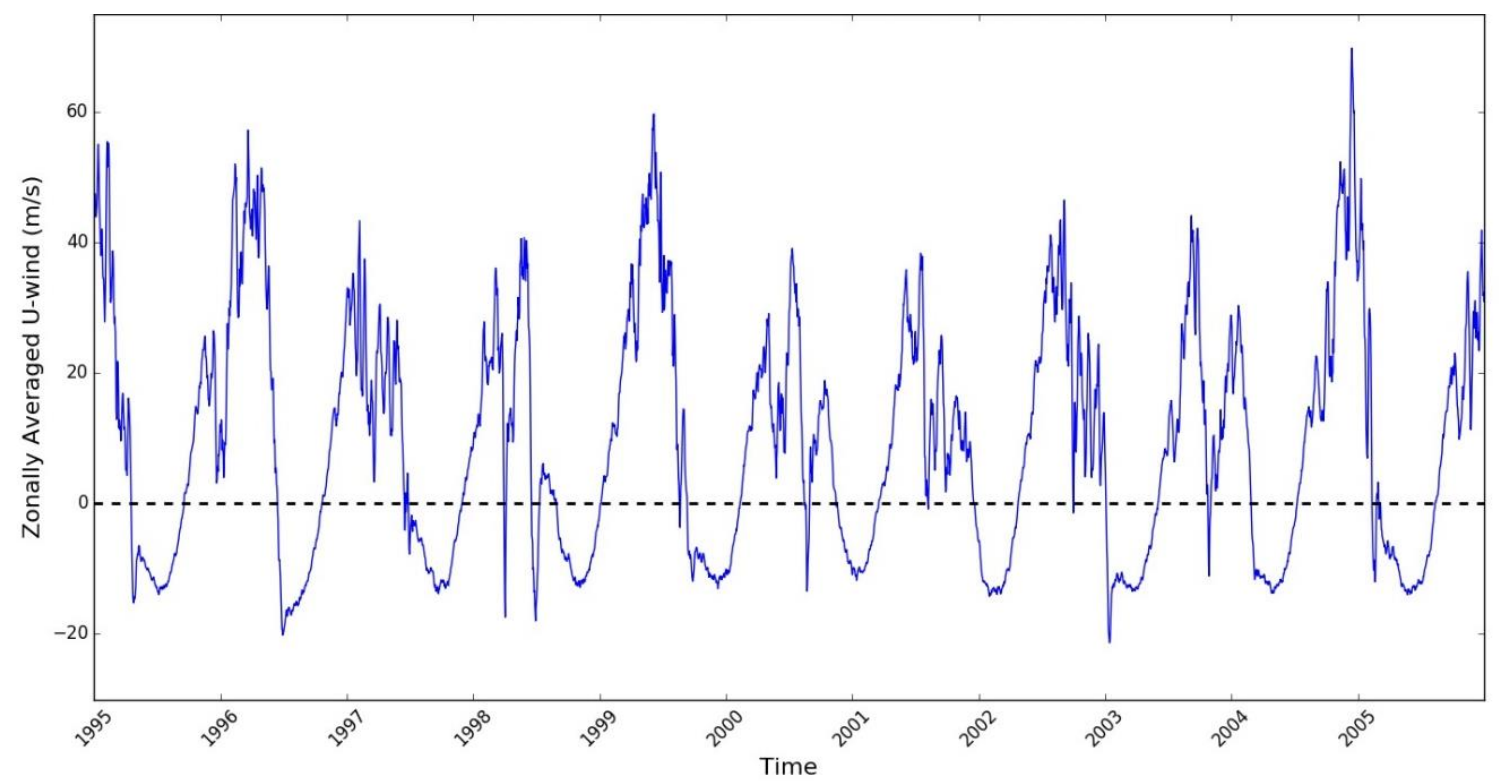

FIG. 6. Daily zonally averaged zonal winds at $60^{\circ} \mathrm{N}$ and $10 \mathrm{hPa}$ from $1995-2005 \mathrm{using}$ NCEP/NCAR Reanalysis data (blue line). The dotted line shows where the zonal wind is zero.

Using the definition determined by Charlton and Polvani (2007), the start of a SSW event is defined as the first day that the zonally averaged zonal wind is easterly in a flow which is otherwise westerly during the winter months (defined here as NovemberMarch). An example of the occurrence of a SSW event is seen in Fig. 7 during the winter of 2000-2001. The zonally averaged zonal wind was a dominant westerly wind and then suddenly it reversed in February to easterly. The reversal of the zonal winds signifies the start of a SSW event and the destabilization of the polar vortex. A few days after the reversal, the vortex was able to stabilize and the flow returned to a westerly wind for the remainder of the winter season. 


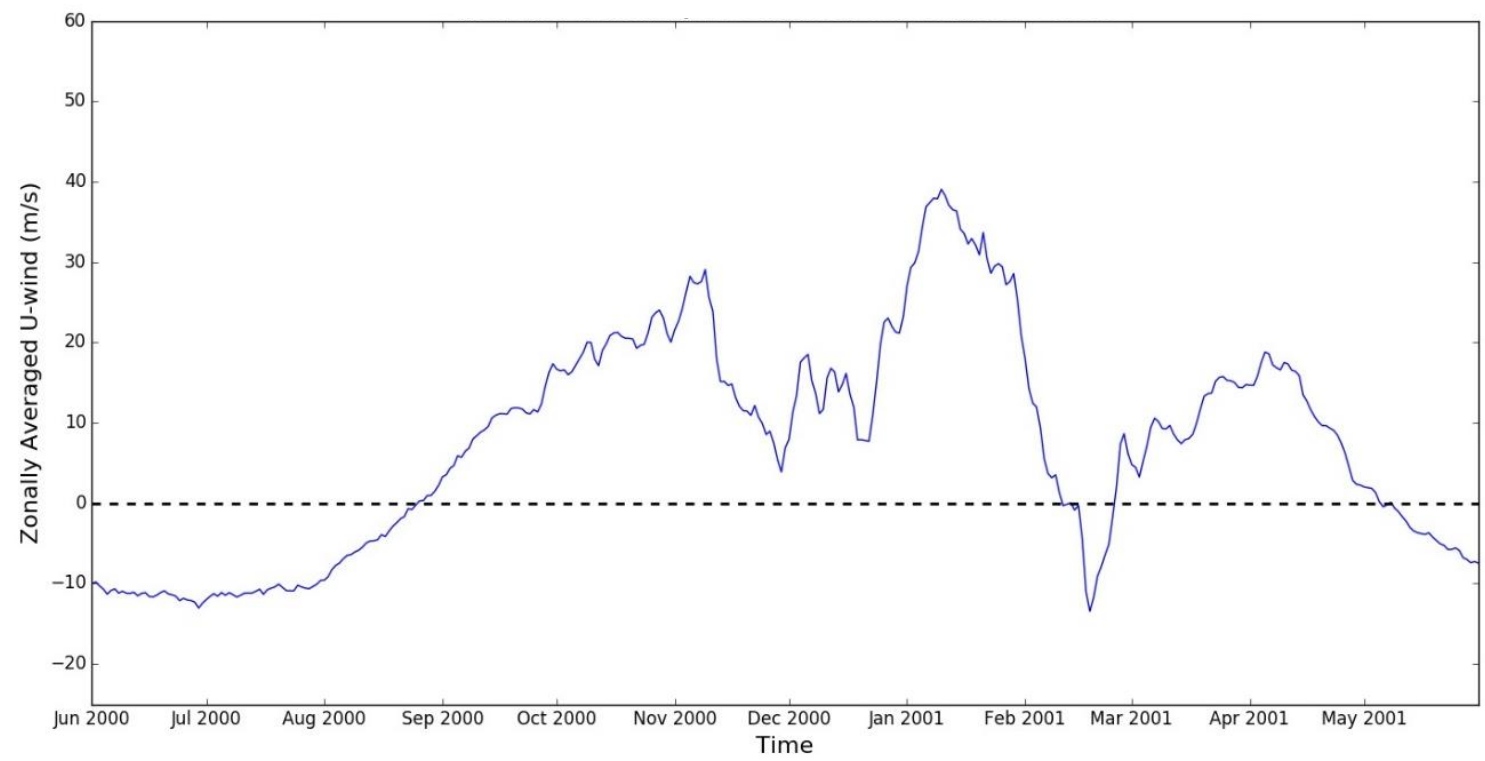

FIG. 7. Daily zonally averaged zonal winds (blue line) at $60^{\circ} \mathrm{N}$ and $10 \mathrm{hPa}$ from June 2000 to June 2001. The dotted line represents where zonal winds are zero.

To further illustrate the difference between winter seasons when a SSW event is observed and not observed, Fig. 8 shows the zonally averaged zonal winds from 1996-1997. During this period, no SSW event was observed, which was clear when the easterly zonal winds shifted to a westerly zonal wind for the entire winter season. The winds remained westerly (although there was variability) and when the warmer season approached, the winds gradually changed to an easterly flow. 


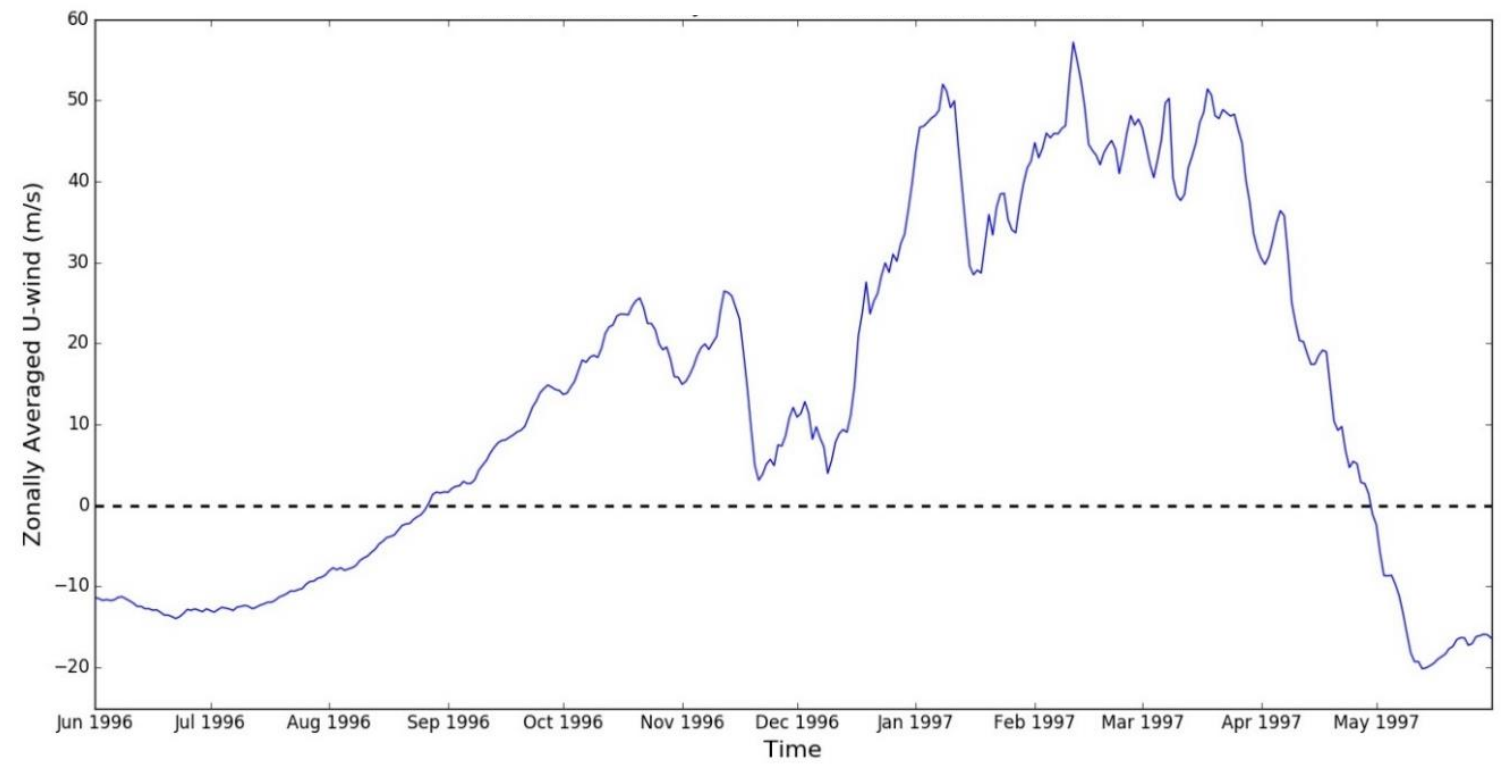

FIG. 8. Daily zonally averaged zonal winds (blue line) at $60^{\circ} \mathrm{N}$ and $10 \mathrm{hPa}$ from June 1996 to June 1997. The dotted line represents where zonal winds are zero.

Using this classification to identify the occurrence of a SSW event, the algorithm was applied to the NCEP/NCAR Reanalysis data from 1950-2005. Based on the reanalysis results, $26 \mathrm{SSW}$ events were identified and occurred with an average of 0.46 events per winter over the 56 year period. The results of this study compare well with past studies that show a similar number of SSW events per year over the historical period (Charlton and Polvani 2007; Butler et al. 2015).

\section{b. CMIP5 historical simulations}

Using four models with historical experiments from CMIP5 (CanESM2, IPSLCM5A-LR, MIROC5, and MPI-ESM-LR) the frequency of SSW events were analyzed historically from 1950-2005. The CMIP5 models used in this study were initialized in the year 1850 and ran for approximately 150 years. For this study, it was not expected that the resulting SSW event dates matched with that of previous studies, nor even between 
the models chosen within this study. Although the timing of SSW events was not expected to align, it was expected that high performing models would accurately simulate the average number of SSW events per winter. The results of this analysis are summarized in Table 2 where they are compared with the NCEP/NCAR Reanalysis results.

TABLE 2. Summary of historical SSW events from 1950-2005. Left to right the columns show the names of the models, the ensemble members, the total number of events, and the average number of events per winter.

\begin{tabular}{llll}
\hline \multirow{2}{*}{ Model } & $\begin{array}{l}\text { Ensemble } \\
\text { Member }\end{array}$ & $\begin{array}{l}\text { Total Number of } \\
\text { Events Found }\end{array}$ & $\begin{array}{l}\text { Average Number of } \\
\text { Events Per Winter }\end{array}$ \\
\hline \multirow{2}{*}{ CanESM2 } & R1 & 58 & 1.04 \\
& R2 & 55 & 0.98 \\
& R3 & 52 & 0.93 \\
\hline \multirow{2}{*}{ IPSL-CM5A-LR } & R1 & 15 & 0.27 \\
& R2 & 23 & 0.41 \\
& R3 & 22 & 0.39 \\
MIROC5 & R1 & 1 & 0.02 \\
& R2 & 1 & 0.02 \\
& R3 & 1 & 0.02 \\
MPI-ESM-LR & R1 & 38 & 0.68 \\
& R2 & 37 & 0.66 \\
NCEP/NCAR & R3 & 35 & 0.63 \\
Reanalysis & & 26 & 0.46 \\
\hline
\end{tabular}

These results indicate significant variance in the frequency of SSW events determined between each model. As shown previously in Table 1, the model tops, number of vertical levels, and resolution vary between each model. Although the models chosen for this study were considered high-top models, the differences in their spatial resolution may contribute to the differences in how each model resolved the stratosphere and how well they were able to resolve the occurrence of a SSW at $10 \mathrm{hPa}$. 
While the reanalysis data identified 26 events and less than one event per winter during the historical time period, models such as the CanESM2 indicated twice this number of events. This is sufficiently different than the results found using the MIROC5 model data that observed one event during the entire 56 year period. On average, the IPSL-CM5 A-LR model, found $0.35 \mathrm{SSW}$ events occurred each winter or once every two to three winters depending on the ensemble member. These IPSL-CM5A-LR results were most similar to the NCEP/NCAR reanalysis data. The MPI-ESM-LR found 0.65 SSW events occurred each winter.

It is known that differences exist between the CMIP5 models used in this study. Figure 9 shows the zonally averaged zonal wind for each model and ensemble member at $60^{\circ} \mathrm{N}$ and $10 \mathrm{hPa}$ for a 10 year period from $1995-2005$. Figure 9 shows that the CanESM2 zonally averaged zonal wind data was the most variable, particularly during the winter season. This may explain the greater frequency in events determined by the CanESM2 since the winds appeared to have more variability compared to the other models. In this figure it is determined that MIROC5 had very little variability during the winter. Shaw et al. (2014) found that MIROC5 exhibited large biases in resolving extreme heat flux events, especially at levels higher than $50 \mathrm{hPa}$. The large biases are consistent with an underestimation of large upward and downward wave coupling and help explain why so few events were found in the MIROC5 model data. 

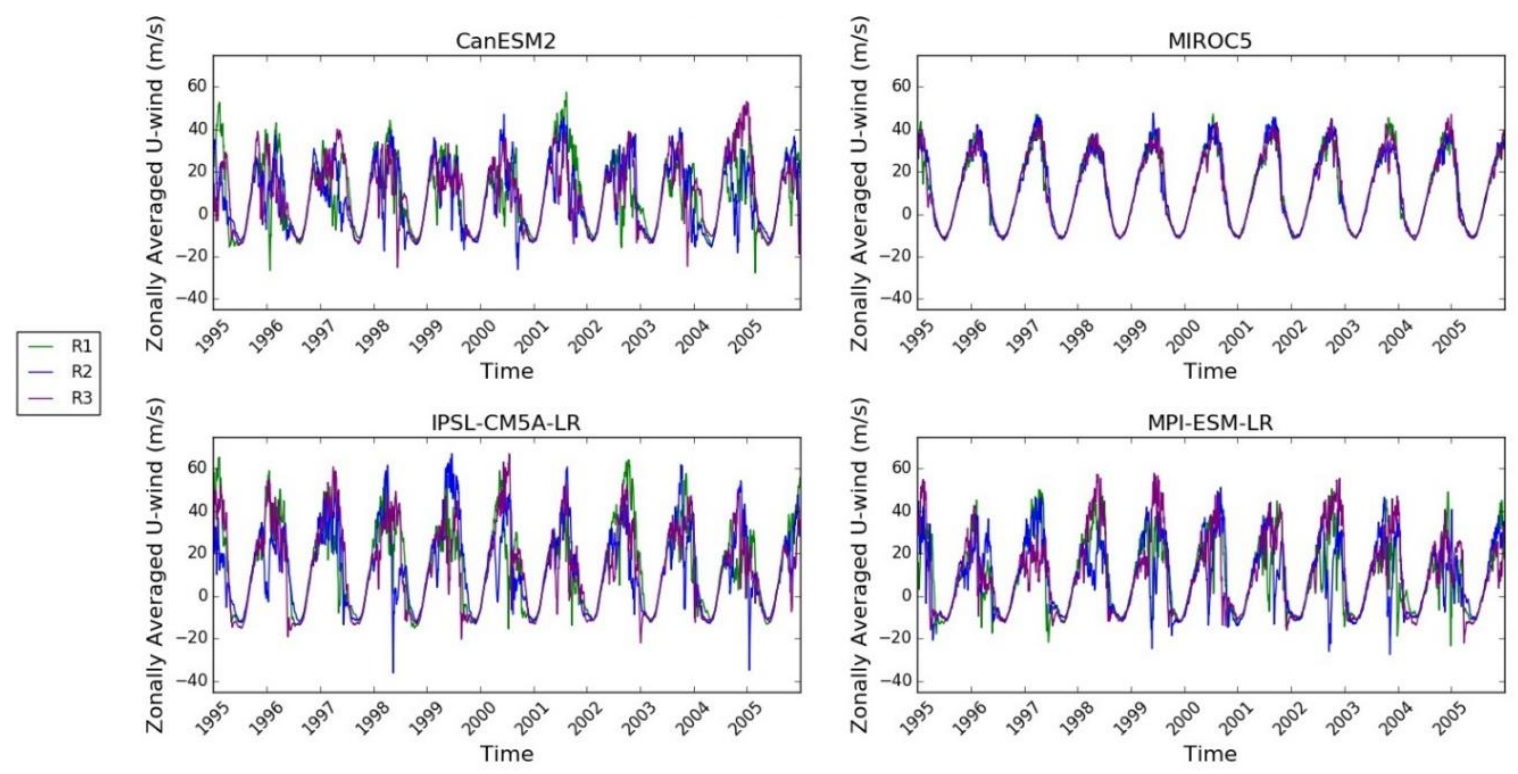

FIG. 9. CMIP5 historical daily zonally averaged zonal winds at $60^{\circ} \mathrm{N}$ and $10 \mathrm{hPa}$ from 1995-2005 for each model and each ensemble member. Ensemble members are represented by 'R1' (green line), 'R2' (blue line), and 'R3' (purple line).

Conclusively, the results from the historical experiments revealed some consistency between models when determining the frequency of SSW events, although variations exist. Two of the models showed a frequency of SSW events similar to the NCEP/NCAR analysis, and one model was higher, but still within a range similar to Earth-like conditions. The MIROC5 model however, lacked the magnitude of variability typically observed, and is outside the range of what might be possible. These differences were likely due to a lack of ability in properly resolving the stratosphere. Since the CanESM2, IPSL-CM5A-LR, and MPI-ESM-LR models were able to resolve the occurrence of SSW events closest to observation, these models are used in the future analysis. The lack of skill shown by MIROC5, has resulted in its exclusion for the remainder of this study when analyzing the number of events found. With minor variability between ensemble 
members, and one event found, there was little confidence in the performance of the MIROC5 for this particular study.

c. Representative concentration pathways 4.5 and 8.5

Using analysis similar to the historical experiments, RCP 4.5 and 8.5 simulations were run from 2006-2100 for four CMIP5 climate models in order to examine the frequency of SSW events in a possible future climate. Although we did not use the MIROC5 model for later analysis, we did include the data in the zonal wind analysis to compare with historical experiments. Figure 10 shows the RCP 4.5 zonally averaged zonal winds at $60^{\circ} \mathrm{N}$ and $10 \mathrm{hPa}$ for all four models over a 10 year period from 20462056 to highlight the variability between the models. The largest amount of variability is observed by the CanESM2, although the IPSL-CM5A-LR had the strongest westerly winds (Fig. 10). Although not shown here, the RCP 8.5 simulations had similar results when analyzing variability between models and ensemble members through the $21^{\text {st }}$ century (See Appendix A). 

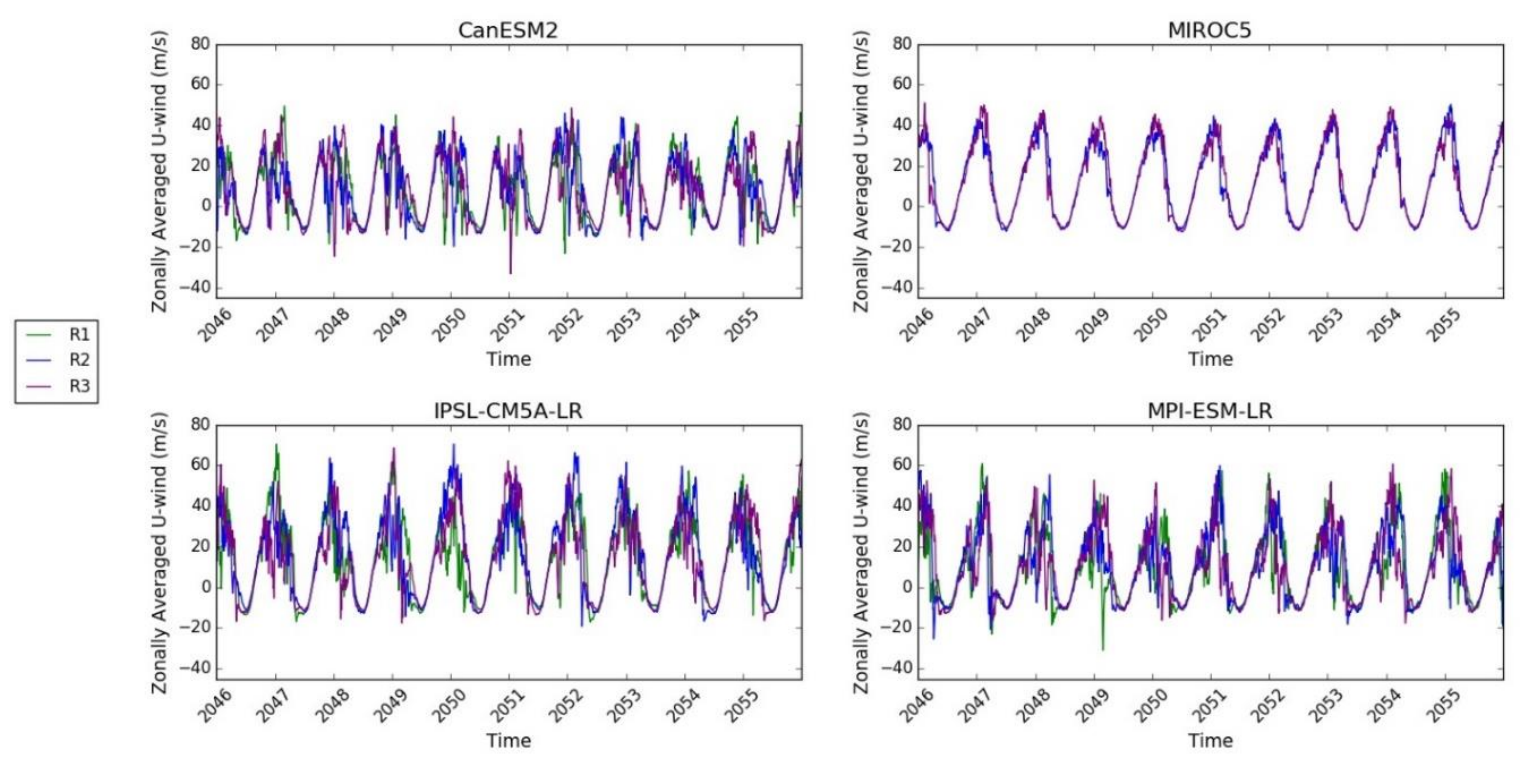

FIG. 10. RCP 4.5 daily zonally averaged zonal winds at $60^{\circ} \mathrm{N}$ and $10 \mathrm{hPa}$ from $2046-$ 2056 for each model and each ensemble member. Ensemble members are represented by 'R1' (green line), 'R2' (blue line), and 'R3' (purple line).

The frequency of SSW events determined by the RCP 4.5 and 8.5 are shown in Table

3. Comparing the two emission scenarios suggests there is neither a decrease nor increase in the number of SSW events found across the models. Some models such as the IPSLCM5 A-LR show a slight increase in frequency with an increased emission scenario, the others such as the CanESM2 and MPI-ESM-LR were similar. 
TABLE 3. Summary of RCP 4.5 and 8.5 SSW events from 2006-2100 for three models with three ensemble members each.

\begin{tabular}{|cc|cc|cc|}
\hline \multirow{2}{*}{ Model } & & \multicolumn{2}{|c|}{ RCP 4.5 } & \multicolumn{2}{c|}{ RCP 8.5 } \\
\cline { 3 - 6 } & $\begin{array}{c}\text { Ensemble } \\
\text { Member }\end{array}$ & $\begin{array}{c}\text { Total } \\
\text { Number } \\
\text { of Events }\end{array}$ & $\begin{array}{c}\text { Average } \\
\text { Number of } \\
\text { Events Per } \\
\text { Winter }\end{array}$ & $\begin{array}{c}\text { Total } \\
\text { Number } \\
\text { of Events }\end{array}$ & $\begin{array}{c}\text { Average } \\
\text { Number of } \\
\text { Events Per } \\
\text { Winter }\end{array}$ \\
\hline \multirow{2}{*}{ CanESM2 } & R1 & 115 & 1.22 & 109 & 1.16 \\
& R2 & 108 & 1.15 & 117 & 1.24 \\
& R3 & 109 & 1.16 & 112 & 1.19 \\
\hline \multirow{2}{*}{ IPSL-CM5A-LR } & R1 & 43 & 0.46 & 46 & 0.49 \\
& R2 & 37 & 0.39 & -- & - \\
\hline \multirow{2}{*}{ MPI-ESM-LR } & R3 & 36 & 0.38 & 56 & 0.60 \\
& R1 & 76 & 0.81 & 72 & 0.77 \\
& R2 & 65 & 0.69 & 70 & 0.74 \\
\hline
\end{tabular}

To further analyze any changes in frequency between the two emission scenarios, a separation of the early-middle century (2006-2050) from the middle-late century (20502100) was performed. These results are summarized in Tables 4 and 5. During the first half of the century, six of the nine runs showed an increase in the number of total events found between the RCP 4.5 and 8.5. The other two runs showed a decrease in the number of total events found between the two scenarios, although a small magnitude. The second ensemble member of the IPSL-CM5A-LR RCP simulations cannot be counted towards these results due to corrupt data in the RCP 8.5 simulation. During the second half of the century, five of the nine ensemble members observed an increase in the frequency of SSW events between the two emission scenarios. A decrease was observed in two runs, and one saw no change. 
TABLE 4. Summary of RCP 4.5 and 8.5 SSW events from 2006-2050 for three models with three ensemble members each.

\begin{tabular}{|c|c|c|c|c|c|}
\hline \multirow[b]{2}{*}{ Model } & \multirow[b]{2}{*}{$\begin{array}{l}\text { Ensemble } \\
\text { Member }\end{array}$} & \multicolumn{2}{|c|}{ RCP 4.5} & \multicolumn{2}{|c|}{ RCP 8.5 } \\
\hline & & $\begin{array}{c}\text { Total } \\
\text { Number } \\
\text { of Events }\end{array}$ & $\begin{array}{c}\text { Average } \\
\text { Number of } \\
\text { Events Per } \\
\text { Winter }\end{array}$ & $\begin{array}{c}\text { Total } \\
\text { Number } \\
\text { of Events }\end{array}$ & $\begin{array}{c}\text { Average } \\
\text { Number of } \\
\text { Events Per } \\
\text { Winter }\end{array}$ \\
\hline \multirow{3}{*}{ CanESM2 } & R1 & 54 & 1.15 & 50 & 1.06 \\
\hline & $\mathrm{R} 2$ & 52 & 1.11 & 55 & 1.17 \\
\hline & R3 & 50 & 1.06 & 53 & 1.13 \\
\hline \multirow{3}{*}{ IPSL-CM5A-LR } & $\mathrm{R} 1$ & 21 & 0.45 & 20 & 0.43 \\
\hline & $\mathrm{R} 2$ & 15 & 0.32 & -- & -- \\
\hline & R3 & 17 & 0.36 & 24 & 0.51 \\
\hline \multirow{3}{*}{ MPI-ESM-LR } & R1 & 31 & 0.66 & 34 & 0.72 \\
\hline & $\mathrm{R} 2$ & 27 & 0.57 & 28 & 0.60 \\
\hline & R3 & 30 & 0.64 & 34 & 0.72 \\
\hline
\end{tabular}

TABLE 5. Summary of RCP 4.5 and 8.5 SSW events from 2050-2100 for three models with three ensemble members each.

\begin{tabular}{|c|c|c|c|c|c|}
\hline \multirow[b]{2}{*}{ Model } & \multirow[b]{2}{*}{$\begin{array}{l}\text { Ensemble } \\
\text { Member }\end{array}$} & \multicolumn{2}{|c|}{ RCP 4.5} & \multicolumn{2}{|c|}{ RCP 8.5 } \\
\hline & & $\begin{array}{c}\text { Total } \\
\text { Number } \\
\text { of Events }\end{array}$ & $\begin{array}{c}\text { Average } \\
\text { Number of } \\
\text { Events Per } \\
\text { Winter }\end{array}$ & $\begin{array}{c}\text { Total } \\
\text { Number of } \\
\text { Events }\end{array}$ & $\begin{array}{c}\text { Average } \\
\text { Number of } \\
\text { Events Per } \\
\text { Winter }\end{array}$ \\
\hline \multirow{3}{*}{ CanESM2 } & R1 & 62 & 1.24 & 60 & 1.2 \\
\hline & $\mathrm{R} 2$ & 57 & 1.14 & 64 & 1.28 \\
\hline & R3 & 59 & 1.18 & 59 & 1.18 \\
\hline \multirow{3}{*}{ IPSL-CM5A-LR } & R1 & 18 & 0.36 & 25 & 0.5 \\
\hline & $\mathrm{R} 2$ & 22 & 0.44 & -- & -- \\
\hline & R3 & 18 & 0.36 & 33 & 0.66 \\
\hline \multirow{3}{*}{ MPI-ESM-LR } & R1 & 45 & 0.9 & 41 & 0.82 \\
\hline & $\mathrm{R} 2$ & 39 & 0.78 & 43 & 0.86 \\
\hline & R3 & 32 & 0.64 & 43 & 0.86 \\
\hline
\end{tabular}

Table 6 provides the calculated change in frequency for each of the RCP scenarios for the early-middle and middle-late century periods. This calculation is the difference between the number of SSW events identified from 2006-2050 and the number of SSW 
events identified from 2050-2100 for RCP 4.5 and 8.5. It is suggested in Table 6 that there was an average change in frequency of $8.51 \%$ between the number of SSW events found in the RCP 4.5 emission scenario between the first and second half of the century. In the RCP 8.5 emission scenario there was an average change in frequency of $15.03 \%$. Between the two scenarios, there was an observed increase in the number of SSW events between the early part and later part of the $21^{\text {st }}$ century. This suggests that with an increased concentration of greenhouse gas emissions and a warmer climate, there is likely to be an increase in the number of SSW events observed in the future.

TABLE 6. Change in SSW event frequency for the RCP 4.5 and 8.5 scenarios between 2006-2050 and 2050-2100. The change in frequency is calculated between three models with three ensemble members each. Ensemble members are listed as 'R1', 'R2', and 'R3'.

\begin{tabular}{|c|c|c|c|}
\hline \multirow[b]{2}{*}{ Model } & \multirow[b]{2}{*}{ Ensemble Member } & RCP 4.5 & RCP 8.5 \\
\hline & & \multicolumn{2}{|c|}{ Change in Frequency (\%) } \\
\hline \multirow{3}{*}{ CanESM2 } & $\mathrm{R} 1$ & 7.34 & 11.35 \\
\hline & $\mathrm{R} 2$ & 2.95 & 8.58 \\
\hline & R3 & 9.84 & 4.44 \\
\hline \multirow{3}{*}{ IPSL-CM5A-LR } & $\mathrm{R} 1$ & -24.11 & 14.89 \\
\hline & $\mathrm{R} 2$ & 27.47 & -- \\
\hline & R3 & 0.00 & 22.63 \\
\hline \multirow{3}{*}{ MPI-ESM-LR } & $\mathrm{R} 1$ & 26.71 & 11.78 \\
\hline & $\mathrm{R} 2$ & 26.35 & 30.73 \\
\hline & R3 & 0.00 & 15.88 \\
\hline \multicolumn{2}{|c|}{ Average \% Change } & 8.51 & 15.03 \\
\hline
\end{tabular}

To summarize the results found in the historical and RCP scenarios, Fig. 11 compares all three experiments based on the average number of events per winter. From this graph it is suggested that for all models except MIROC5, there was an increase in the number 
of SSW events between historical and future experiments. This increase, although not substantial, may be indicative of what is expected in the future. Based on these results, the CanESM2 appeared to overproduce the frequency of events, and the MIROC5 underproduced SSW events. MPI-ESM-LR and IPSL-CM5A-LR were closest to observation and may provide the most reliable results in this analysis.
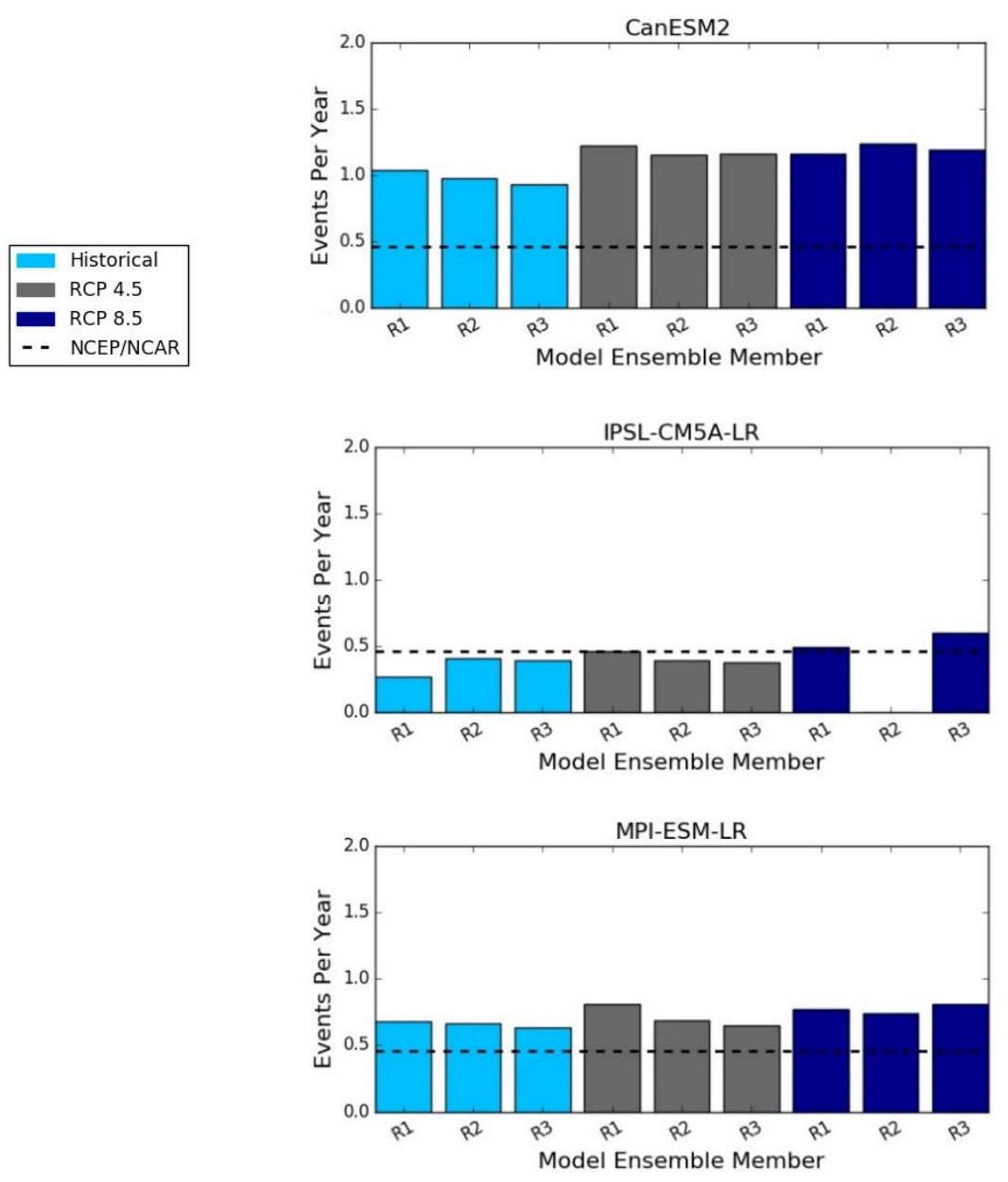

FIG. 11. Average number of SSW events per winter for each model, ensemble member, and scenario; historical (light blue), RCP 4.5 (gray), and RCP 8.5 (dark blue).

NCEP/NCAR reanalysis results are annotated (black dotted line). Ensemble members are represented as 'R1','R2', and 'R3'. MIROC5 data not included. 


\section{d. Statistical analysis}

To determine if the results of this study are statistically significant for the last 50 years of data, 6 student's two-tailed paired t-tests were done. Historically, this was from 1955-2005 and for RCP 4.5 and 8.5 it was from 2050-2100. For each t-test, the ensemble averages were compared between historical and emission scenarios. The ensemble average was calculated by finding the average number of SSW events per winter over the 50 year period for each ensemble member of each model. The results of all t-tests can be found in Table 7. When comparing the ensemble averages between the historical and RCP 8.5 emission scenario for each model, the differences were statistically significant at the $91 \%$ confidence level. For the historical and RCP 4.5 emission scenario, the difference between CanESM2 ensemble averages were statistically different at the $95 \%$ confidence level. In contrast, there is not a statistical difference between MPI-ESM-LR ensemble averages and the IPSL-CM5A-LR ensemble averages. Although the historical and RCP 4.5 IPSL-CM5A-LR results indicate substantial similarities, it can be concluded that the overall changes in SSW event frequency observed across all models is statistically significant, especially in the higher emission scenario. 
TABLE 7. The description and results of 6 two-tailed paired t-tests using historical ensemble averages from 1955-2005 and RCP 4.5 and 8.5 ensemble averages from 20502100 .

\begin{tabular}{ccc}
\hline \multicolumn{2}{c|}{ Datasets Compared } & P-Value \\
\hline Historical CanESM2 & RCP 4.5 CanESM2 & 0.0486 \\
\hline Historical IPSL-CM5A-LR & RCP 4.5 IPSL-CM5 A-LR & 0.8743 \\
\hline Historical MPI-ESM-LR & RCP 4.5 MPI-ESM-LR & 0.2601 \\
\hline Historical CanESM2 & RCP 8.5 CanESM2 & 0.0048 \\
\hline Historical IPSL-CM5A-LR & RCP 8.5 IPSL-CM5A-LR & 0.0826 \\
\hline Historical MPI-ESM-LR & RCP 8.5 MPI-ESM-LR & 0.0187 \\
\hline
\end{tabular}

Conclusively, based on the analysis of CMIP5 models used in this study, the frequency of SSW events is likely to increase in the future. However, it remains unclear how many more events will likely be observed. The variability between models has made this question difficult to answer. It is found that using MPI-ESM-LR and IPSL-CM5 ALR may be the most reliable in resolving SSW events closest to reality.

\section{Conclusion}

Starting with the dawn of the industrial revolution, the concentration of greenhouse gases in the Earth's atmosphere has been exponentially increasing. Linked to the increase in greenhouse gas concentrations, the Arctic has been warming at a faster rate than any other part of the globe (known as Arctic amplification), leading to a significant loss of Arctic sea ice. This warming has led to a decrease in the meridional temperature gradient in the lower troposphere and an increase in the upper troposphere. While there is evidence that Arctic amplification may modulate midlatitude circulation responses, it will 
not be the sole driver. As a result of changes in meridional temperature gradient both in the upper and lower troposphere, the stratospheric circulation may be sensitive to any changes as it is intimately coupled with the troposphere.

Driven primarily by enhanced Rossby wave activity, SSW events are able to impact tropospheric weather in many ways. Anomalous vertically propagating Rossby waves interact with the mean zonal flow, causing a disruption and reversal of the mean zonal winds. Slowing the eastward propagation of Rossby waves, the midlatitude jet stream becomes meridionally amplified and cold Arctic air surges equatorward, impacting human health and agriculture. This study investigated how the frequency of SSW events, a key feature in the stratosphere during the northern hemisphere winter, may be impacted by climate change.

Using four models with historical experiments from CMIP5 (CanESM2, IPSLCM5A-LR, MIROC5, and MPI-ESM-LR) and applying the algorithm developed by Charlton and Polvani (2007), the frequency of SSW events was analyzed historically from 1950-2005. To verify that the algorithm could effectively resolve SSW events, NCEP/NCAR reanalysis data were used to create a climatology of SSW events from 1950-2005. Using NCEP/NCAR reanalysis data, 26 events were identified during the historical period, which is in agreement with results found in previous studies (Butler et al. 2015; Charlton and Polvani 2007). In addition, the zonally averaged zonal winds were analyzed in four CMIP5 models in the RCP 4.5 and 8.5 experiments from 2006-2100. The MIROC5 model was discarded as a result of the inability to resolve SSW events. Shaw et al. (2014) found that MIROC5 underestimates downward and upward wave 
coupling, which likely led to the lack of confidence in resolving SSW events in this study. The four models used in this study have not been used to assess the frequency of SSW events prior to this publication.

The results of this study reveal there is an increase in the number of SSW events between historical and future experiments. Of the four models used in this study, the CanESM2 appears to overproduce the frequency of SSW events, and the MIROC5 underproduces SSW events. MPI-ESM-LR and IPSL-CM5A-LR are closest to observation and provide the most reliable results in this analysis. As a result of Arctic amplification and sea ice losses, Kim et al. (2014) found that vertically propagating planetary scale waves are enhanced, which weaken the polar vortex during the winter months. Since Arctic amplification is expected to persist in the future causing further sea ice melting, and SSW events are driven by anomalous Rossby waves, it can be assumed that the enhanced wave activity is the likely cause of increased frequency of SSW events found in this study.

Two-tailed paired t-tests revealed that there is a statistically significant difference between the historical and RCP 8.5 ensemble averages. In conclusion, the results of this study show the frequency of SSW events will increase in the future based on the CMIP5 model results, especially in the higher emission scenario. Further research should be done to test SSW frequency with other coupled climate models to see if these results are consistent with other initialization and physics schemes.

Expanding the work of this study would be advantageous for furthering research on SSW events. Using models with improved resolution of the stratosphere and higher lid 
tops may be useful for capturing SSW events more effectively. The models used in this study are considered high-top models with lid tops well into and above the stratosphere; by including more vertical levels and/or increasing the lid top of the models, there may be improved model skill when resolving SSW events. The effects of ocean-atmosphere coupling on the frequency of SSW events were outside the scope of this study, but remain an area requiring further research. Since SSW events occur directly over the Arctic Ocean, declining sea ice trends are expected to impact the amount of heat and moisture exchanged between the stratosphere and troposphere. 


\section{References}

Andrews, D. G., J. R. Holton, and C. B. Leovy, 1985: Middle atmosphere dynamics. Academic Press, 489.

Baldwin, M. P., and T. J. Dunkerton, 2001: Stratospheric harbingers of anomalous weather regimes. Science, 294, 581-584.

Bancala, S., K. Kruger, and M. Giogetta, 2012: The preconditioning of major sudden stratospheric warmings. J. Geophys. Res, 117, D4, doi: 10.1029/2011JD016769.

Barnes, E. A., and L. M. Polvani, 2015: CMIP5 projections of Arctic amplification, of the North American/North Atlantic circulation, and of their relationship. $J$. Climate, 28, 5254-5271.

Blume, C., K. Matthes, and I. Horenko, 2012: Supervised learning approaches to classify sudden stratospheric warming events. J. Atmos. Sci., 69, 1824-1840.

Butler, A., D. Seidel, S. Hardiman, N. Butchart, T. Birner, and A. Match, 2015: Defining sudden stratospheric warmings. Bull. Amer. Meteor. Soc., 96, 1913-1928.

Bridger, A. F., and D. Stevens, 1981: Numerical modeling of the stratospheric sudden warming: some sensitivity studies. J. Atmos. Sci., 39, 666-679.

Cai, D., G. Dameris, H. Garny, and T. Runde, 2012: Implications of all season Arctic seaice anomalies on the stratosphere. Atmos, Chem. Phys., 12, 11819-11831.

Charlton, A. J., and L. M Polvani, 2007: A new look at stratospheric sudden warming. Part I: Climatology and benchmarks. J. Climate, 20, 3, 449-469.

Charlton-Perez, A., and Coauthors, 2013: On the lack of stratospheric dynamics variability in low-top versions of the CMIP5 models. J. Geophys. Res, 118, 24942505.

Charney, J.G., and P.G. Drazin, 1961: Propagation of planetary-scale disturbances from the lower into the upper atmosphere. J. Geophys. Res., 66, 83-109

Cohen, J., and J. Jones, 2011: Tropospheric precursors and stratospheric warmings. $J$. Climate, 24, 6562-6572.

Coughlin, K. and L. J. Gray, 2009: A continuum of sudden stratospheric warmings. $J$. Atmos. Sci., 66, 531-540.

Deser, C., A. Tomas, and L. Sun, 2014: The role of ocean-atmosphere coupling in the zonal-mean atmospheric response to Arctic sea ice loss. J. Climate, 28, 2168- 2186. 
Esler, J. G., Polvani, L. M., and R. K. Scott, 2006: The Antarctic sudden stratospheric warming of 2002: A self-tuned resonance?. Geophys. Res. Let., 33, doi:10.1029/2006GL026034.

Gerber, E. P., and L. M. Polvani, 2009: Stratospheric-tropospheric coupling in a relatively simple AGCM: The importance of stratospheric variability. J. Climate, 22, 1920-1933.

Hibbard, K. A., D. P. van Vuuren, and J. Edmonds, 2011: A primer on the representative concentration pathways (RCPs) and the coordination between the climate and integrated assessment modeling communities: CLIVAR Exchanges, 56, 16, 2, 12- 15.

Jaiser, R., K. Dethloff, R. Handorf, 2013: Stratospheric response to the Arctic sea ice retreat and associated planetary wave propagation changes. Tellus A., 65, 1-11.

Jakobson, E., and Coauthors, 2012: Validation of atmospheric reanalysis over the central Arctic Ocean. Geophys. Res. Let., 39, L10802, doi:10.1029/2012GL051591

Kalnay, E., and Coauthors, 1996: The NCEP/NCAR 40-year reanalysis project. Bull. Amer. Meteor. Soc., 77, 437-470.

Kim, B., and Coauthors, 2014: Weakening of the stratospheric polar vortex by Arctic sea ice loss. Nat. Commun., 5, 4646, doi:10.1038/ncomms5646

Lee, Y-Y, and R. Black, 2015: The structure and dynamics of the stratospheric northern annular mode in CMIP5 simulations. J. Climate, 28, 1, 86-107.

Limpasuvan, V., D. Thompson, and D. Hartmann, 2004: The life cycle of the Northern Hemisphere sudden stratospheric warmings. J. Climate, 17, 2584-2596.

Manzini, E., and Coauthors, 2014: Northern winter climate change: Assessment of uncertainty in CMIP5 projections related to stratosphere-troposphere coupling. $J$. Climate, 119, 13, 7979-7998.

Matsuno, T., 1971: A dynamical model of the sudden stratospheric warming. J. Atmos. Sci., 28, 1479-1494.

McGuirk, J., and D. Douglas, 1988: Sudden stratospheric warming and anomalous U.S. weather. Mon. Wea. Rev., 116, 162-174.

O'Callaghan, A., J. Manoi, D. Stevens, and D. Mitchell, 2014: The effects of different sudden stratospheric warming types on the ocean. Geophys. Res. Let., 41, 21, 7739-7745. 
Overland, J., J. Francis, R.Hall, E. Hanna, S-J. Kim, and T. Vihma, 2015: The melting Arctic and midlatitude weather patterns: Are they connected? J. Climate, 28, 7917-7931.

Overland, J., and M. Wang, 2010: Large-scale atmospheric circulation changes associated with the recent loss of Arctic sea ice. Tellus, 62A, 1-9.

Peings, Y., and G. Magnusdottir, 2013: Response of the wintertime Northern Hemisphere atmospheric circulation to current and projected Arctic sea ice decline: A numerical study with CAM5. J. Climate, 27, 244-264.

Polvani, L. M., and D. W. Waugh, 2004: Upward wave activity flux as a precursor to extreme stratospheric events and subsequent anomalous surface weather regimes. J. Climate, 17, 3548-3554.

Scherhag, R., 1952: Die explosionsartigen stratosphärenerwärmungen des spätwinters 1951-1952. Ber. Dtsch. Wetterdienst (US Zone), 6, 51-63.

Schoeberl, M., 1978: Stratospheric warmings: Observations and theory. Rev. Geophys. Space Phys., 16, 521-538.

Screen, J. A., C. Deser, and I. Simmonds, 2012: Local and remote controls on observed Arctic warming. Geophys. Res. Let., 39, doi: 10.1029/2012GL051598

Screen, J. A., C. Deser, and I. Simmonds, 2013: Atmospheric impacts of Arctic sea-ice loss, 1979-2009: separating forced change from atmospheric internal variability. Clim. Dyn, 333-344.

Screen, J.A., C. Deser, and L. Sun., 2015: Reduced risk of North American cold extremes due to continued arctic sea ice loss. Bull. Amer. Met. Soc., 96, 1489-1503.

Shaw, T. A., and J. Perlwitz, 2013: The life cycle of northern hemisphere downward wave coupling between the stratosphere and troposphere. J. Climate, 26, 1745-1763.

Shaw, T. A., J. Perlwitz, and O. Weiner, 2014: Tropospheric-stratospheric coupling: Links to North Atlantic weather and climate, including their representation in CMIP5 models. J. Geophys. Res., 119, 5864-5880.

Stocker, T., and Coauthors, 2013: Climate Change 2013: The physical science basis. Cambridge University Press, 1535.

Stouffer, R. J., K. E. Taylor, and G. A. Meehl, 2011: CMIP5 long-term experimental design: CLIVAR Exchanges, 56, 16, 2, 5-7. 
Taguchi, M., 2008: Is there a statistical connection between stratospheric sudden warming and tropospheric blocking events? J. Atmos. Sci., 65, 1442-1454

Taylor, K. E., R. Stouffer, and G. A. Meehl, 2012: An overview of CMIP5 and the experimental design. Bull. Amer. Meteor. Soc., 93, 485-498.

Vihma, T., 2014: Effects of Arctic sea ice decline on weather and climate: A Review. Surv. Geophys, 35, 1175-1214.

Waugh, D. W., and L. M. Polvani, 2010: Stratospheric polar vortices. The Stratosphere: Dynamics, Transport, and Chemistry, Geophys. Monogr. Ser., 190, 43-57, American Geophysical Union, Washington, D.C. doi:10.1029/2009GM000887. 
APPENDIX A: Additional Figures
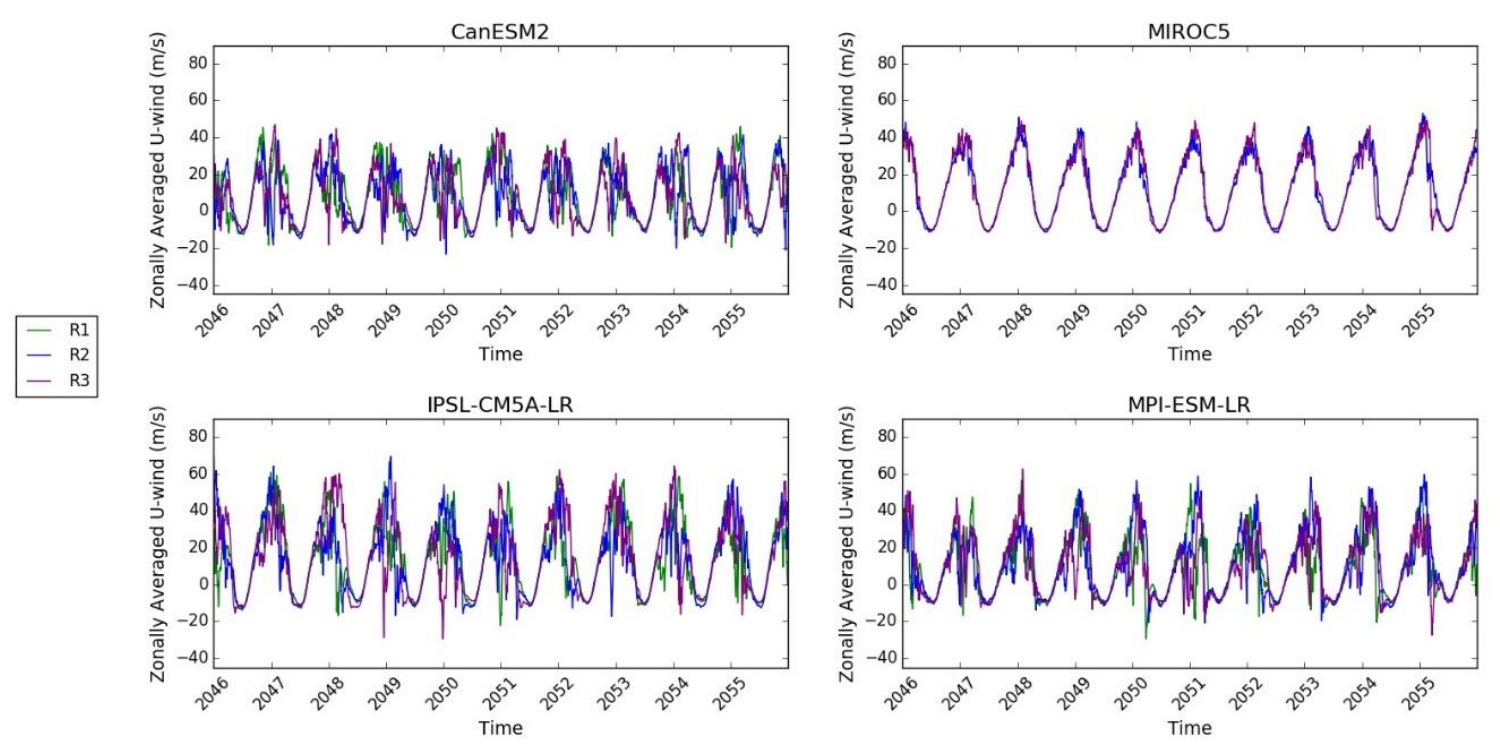

FIG. A1. RCP 8.5 daily zonally averaged zonal winds at $60^{\circ} \mathrm{N}$ and $10 \mathrm{hPa}$ from 20462056 for each model and each ensemble member. Ensemble members are represented by 'R1' (green line), 'R2' (blue line), and 'R3' (purple line). 